\title{
Phase formation and texture of thin nickel germanides on $\mathrm{Ge}(001)$ and $\mathrm{Ge}(111)$
}

B. De Schutter, K. Van Stiphout, N. M. Santos, E. Bladt, J. Jordan-Sweet, S. Bals, C. Lavoie, C. M. Comrie, A. Vantomme, and C. Detavernier

Citation: Journal of Applied Physics 119, 135305 (2016);

View online: https://doi.org/10.1063/1.4945317

View Table of Contents: http://aip.scitation.org/toc/jap/119/13

Published by the American Institute of Physics

\section{Articles you may be interested in}

Texture in thin film silicides and germanides: A review

Applied Physics Reviews 3, 031302 (2016); 10.1063/1.4960122

Formation of nickel germanides from Ni layers with thickness below $10 \mathrm{~nm}$

Journal of Vacuum Science \& Technology B, Nanotechnology and Microelectronics: Materials, Processing,

Measurement, and Phenomena 35, 020602 (2017); 10.1116/1.4975152

Reaction of Ni film with $\operatorname{In}_{0.53} \mathrm{Ga}_{0.47} \mathrm{As}$ : Phase formation and texture

Journal of Applied Physics 120, 135304 (2016); 10.1063/1.4963716

Thin film reaction of transition metals with germanium

Journal of Vacuum Science \& Technology A: Vacuum, Surfaces, and Films 24, 474 (2006); 10.1116/1.2191861

Reaction of thin Ni films with Ge: Phase formation and texture

Journal of Applied Physics 100, 034306 (2006); 10.1063/1.2219080

High Curie temperature $\mathrm{Mn}_{5} \mathrm{Ge}_{3}$ thin films produced by non-diffusive reaction

Applied Physics Letters 110, 072408 (2017); 10.1063/1.4976576

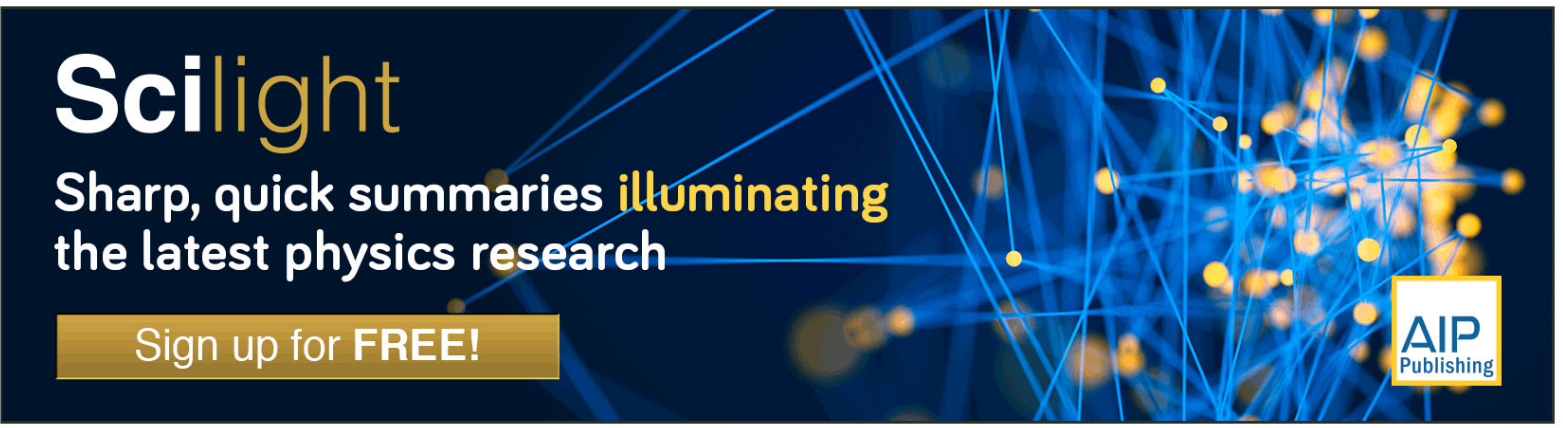




\title{
Phase formation and texture of thin nickel germanides on $\mathrm{Ge}(001)$ and $\mathrm{Ge}(111)$
}

\author{
B. De Schutter, ${ }^{1, a)}$ K. Van Stiphout, ${ }^{2}$ N. M. Santos, ${ }^{2}$ E. Bladt, ${ }^{3}$ J. Jordan-Sweet, ${ }^{4}$ S. Bals, ${ }^{3}$ \\ C. Lavoie, ${ }^{4}$ C. M. Comrie, ${ }^{5, b)}$ A. Vantomme, ${ }^{2}$ and C. Detavernier ${ }^{1}$ \\ ${ }^{1}$ Department of Solid-State Sciences, Ghent University, Krijgslaan 281/S1, 9000 Ghent, Belgium \\ ${ }^{2}$ Instituut voor Kern- en Stralingsfysica, KU Leuven, Celestijnenlaan 200 D, B-3001 Leuven, Belgium \\ ${ }^{3}$ Electron Microscopy for Materials Research (EMAT), University of Antwerp, Groenenborgerlaan 171, \\ B-2020 Antwerp, Belgium \\ ${ }^{4}$ IBM T.J. Watson Research Center, Yorktown Heights, New York 10598, USA \\ ${ }^{5}$ Department of Physics, University of Cape Town, Rondebosch 7700, South Africa
}

(Received 18 January 2016; accepted 21 March 2016; published online 5 April 2016)

\begin{abstract}
We studied the solid-phase reaction between a thin Ni film and a single crystal Ge(001) or Ge(111) substrate during a ramp anneal. The phase formation sequence was determined using in situ X-ray diffraction and in situ Rutherford backscattering spectrometry (RBS), while the nature and the texture of the phases were studied using X-ray pole figures and transmission electron microscopy. The phase sequence is characterized by the formation of a single transient phase before NiGe forms as the final and stable phase. X-ray pole figures were used to unambiguously identify the transient phase as the $\epsilon$-phase, a non-stoichiometric Ni-rich germanide with a hexagonal crystal structure that can exist for Ge concentrations between $34 \%$ and $48 \%$ and which forms with a different epitaxial texture on both substrate orientations. The complementary information gained from both RBS and X-ray pole figure measurements revealed a simultaneous growth of both the $\epsilon$-phase and NiGe over a small temperature window on both substrate orientations. (C) 2016 AIP Publishing LLC.
\end{abstract}

[http://dx.doi.org/10.1063/1.4945317]

\section{INTRODUCTION}

In modern MOSFET (Metal-Oxide-Semiconductor Field Effect Transistor) devices, the limitations of classical dimensional downscaling force scientists and engineers to come up with innovative approaches in order to maintain the continuous improvement of device performance. This has resulted in many material innovations such as the use of strained silicon in the channel region of the MOSFET (e.g., by replacing Si by $\mathrm{Si}_{1-x} \mathrm{Ge}_{x}$ in the source and drain regions) and the replacement of the $\mathrm{SiO}_{2}$ /polycrystalline silicon gate by a high-k/metal gate. More recently, alternative channel materials like $\mathrm{Si}_{1-x} \mathrm{Ge}_{x}$ are being adopted in industry and research is now focussing on increasing the Ge content in these channels or even adopting pure $\mathrm{Ge}$ as a channel material, as both $\mathrm{Si}_{1-x} \mathrm{Ge}_{x}$ and pure Ge have much higher carrier mobilities compared to $\mathrm{Si}^{1-5}$ In this context, thin film germanides $(1-30 \mathrm{~nm})$ appear as a natural candidate to act as contacting material for the germanium-rich source and drain regions. ${ }^{6}$

In 2006, Gaudet et al. identified NiGe as an ideal contacting material mainly because of its low resistivity $(\sim 22 \mu \Omega \mathrm{cm})$ and low nucleation temperature (around $350^{\circ} \mathrm{C}$ at $\left.1{ }^{\circ} \mathrm{C} / \mathrm{s}\right) .{ }^{6}$ Similar to the case of widely used silicide contacts, the formation of such a $\mathrm{NiGe}$ contact proceeds through a solid-phase reaction between a thin $\mathrm{Ni}$ film and a Ge substrate upon annealing. This reaction has been studied by a number of groups on different types of Ge substrates such as

\footnotetext{
${ }^{\text {a)} E l e c t r o n i c ~ m a i l: ~ d e s c h u t t e r . b o b @ u g e n t . b e ~}$

b) Present address: iThemba LABs, National Research Foundation, PO box 722, Somerset West 7129, South Africa.
}

amorphous Ge (a-Ge), ${ }^{7-10}$ polycrystalline Ge (poly-Ge), ${ }^{8,9}$ $\mathrm{Ge}(001)^{6,10}$ and $\mathrm{Ge}(111){ }^{10-12}$ It is generally accepted that the reaction sets off with the formation of a Ni-rich germanide. Afterwards, this Ni-rich phase is consumed by the growth of the NiGe end phase. In the literature, disagreement exists concerning the identification of the Ni-rich phase. Earlier studies report it as $\mathrm{Ni}_{2} \mathrm{Ge}$ or $\mathrm{Ni}_{3} \mathrm{Ge}_{2}{ }^{11,12}$ while in the more recent reports, orthorhombic $\epsilon^{\prime}-\mathrm{Ni}_{5} \mathrm{Ge}_{3}$ is suggested. ${ }^{8,10}$ Furthermore, a temperature window was observed in which the Ni-rich and NiGe phases grow simultaneously on a-Ge, poly-Ge and $\mathrm{Ge}(001){ }^{8,10}$ while sequential growth was observed on $\mathrm{Ge}(111) .{ }^{10}$

In this study, we performed a detailed analysis of the phase formation sequence during a solid-phase reaction between a $30 \mathrm{~nm} \mathrm{Ni}$ film and a single crystal Ge(001) or (111) substrate, with a focus on the nature of the Ni-rich phase, using in situ X-ray diffraction (XRD). By performing a detailed study on the texture of this phase at different temperatures, we are able to unambiguously identify it as the " $\epsilon$-phase," a hexagonal Ni-rich germanide that can exist over a broad composition range and that is known to be stable only above $300^{\circ} \mathrm{C}$ in the bulk Ni-Ge system. In addition, we used transmission electron microscopy (TEM) to assess the morphology of the interface during the reaction and Rutherford backscattering spectrometry (RBS) to study the kinetics during the reactions.

\section{EXPERIMENTAL}

Polycrystalline thin films of $30 \mathrm{~nm} \mathrm{Ni}$ were deposited on both single crystalline $\mathrm{Ge}(100)$ and $\mathrm{Ge}(111)$ substrates using 
magnetron sputtering. The sputter chamber was pumped to a base pressure of $4 \times 10^{-6}$ mbar prior to deposition and the argon pressure during deposition was fixed at $5 \times 10^{-3} \mathrm{mbar}$.

To investigate the phase formation sequence, in situ XRD was performed at the X20C beamline of the National Synchrotron Lightsource (NSLS) at Brookhaven National Lab (BNL). ${ }^{6,10,13-15}$ The samples were subjected to an anneal from 100 to $900^{\circ} \mathrm{C}$ at a rate of $1{ }^{\circ} \mathrm{C} / \mathrm{s}$ in a high purity helium flow. During this anneal, the phase sequence was recorded through XRD using monochromatic X-rays with a wavelength of $1.797 \AA$. The diffraction pattern was recorded every second using a linear detector with a $2 \theta$ window of $14^{\circ}$, which is fixed at a certain $2 \theta$ angle. For both types of substrate, samples were measured twice with the detector first centered at $42^{\circ}$ and then at $55^{\circ}$ to fully cover $2 \theta$ values reaching from $35^{\circ}$ to $62^{\circ}$, effectively targeting lattice planes with a $d$-spacing ranging from 1.745 to $2.988 \AA$.

As our in situ experiment is performed with a fixed $\theta / 2 \theta$ geometry, it accesses only a very small fraction of possible diffracting grains. Indeed, because the position of sample and detector remains fixed during the measurement, only those grains having the diffracting plane (nearly) parallel to the substrate surface will be visible in the resulting XRD pattern. As a result, strongly textured phases consisting of grains that have a specific lattice plane parallel to the substrate surface are possibly characterised by only a single peak or might not be visible at all in the XRD data (i.e., if the diffraction conditions for that plane are not fulfilled in the given fixed geometry).

In order to unambiguously identify the phases present at different stages of the solid-phase reaction and to study their texture, complete pole figures were measured on samples quenched at different stages of the reaction, both on $\mathrm{Ge}(001)$ and on $\mathrm{Ge}(111)$ substrates. These pole figures were recorded at the X20A beamline of the NSLS synchrotron using a high-range linear Si-strip detector which effectively collects 640 pole figures in a single measurement for a $2 \theta$ range from $20^{\circ}$ to $60^{\circ}(\lambda=1.54 \AA)$. The pole figures were measured using a $1^{\circ}$ stepsize in $\chi$ (sample tilting) and an adaptive stepsize in $\phi$ (sample rotation) in order to obtain a uniform pole figure coverage. Accounting for the substrate symmetry, $\phi$ was measured between $0^{\circ}$ and $90^{\circ}$ for the $\mathrm{Ge}(001)$, and between $0^{\circ}$ and $120^{\circ}$ for the $\mathrm{Ge}(111)$ substrate, $\chi$ was measured between $0^{\circ}$ and $90^{\circ}$ in both cases.

Next to the X-ray diffraction techniques used to identify the crystal structure of the different phases in the sequence, in situ RBS was used to complement these results with elemental depth information. In thin film research, RBS is a powerful and well-established technique as it provides quantitative information on elemental composition and depth. Applying this technique in situ during an anneal allows one to accurately probe the atomic diffusion process and the thickness evolution of the growing and shrinking phases during the phase formation sequence that results from the heat treatment. $^{16-18}$ The in situ RBS measurements were performed in a vacuum chamber with a pressure below $10^{-7}$ mbar using a two-stage ramp anneal. First, a fast ramp rate of $20^{\circ} \mathrm{C} / \mathrm{min}$ to about $110^{\circ} \mathrm{C}$ was used to reduce the measuring time prior to the onset of the solid-phase reaction.
Next, the reaction itself was monitored at a slower ramp rate of $2{ }^{\circ} \mathrm{C} / \mathrm{min}$ from $110^{\circ} \mathrm{C}$ until the film had completely transformed in $\mathrm{NiGe}$, i.e., $350^{\circ} \mathrm{C}$ on $\mathrm{Ge}(001)$ and $437^{\circ} \mathrm{C}$ on $\mathrm{Ge}(111)$. During the annealing, RBS spectra were collected using a $2 \mathrm{MeV}^{4} \mathrm{He}^{+}$beam with a beam current of $38 \mathrm{nA}$. Backscattered ions were detected using two detectors placed at scattering angles of $150^{\circ}$ and $165^{\circ}$ (to optimize depth and mass resolution) and the sample normal was tilted $40^{\circ}$ with respect to the incoming ion beam to enhance the depth resolution. RBS spectra were acquired every $30 \mathrm{~s}$ during the annealing. To obtain sufficient statistics, the spectra are summed in groups of 4 for analysis, resulting in one spectrum every $2 \mathrm{~min}$ and a temperature resolution of $4{ }^{\circ} \mathrm{C}$. In order to optimize the depth resolution and the statistics in the in situ RBS measurements, samples were used with a $\mathrm{Ni}$ thickness of $60 \mathrm{~nm}$.

Finally, TEM imaging was performed on cross-sections of the interface between the Ge substrate and the Ni film for selected quenches in order to assess the interface morphology. Furthermore, Fourier transforms of high resolution TEM images acquired on the same quenches enable us to complement the phase identification results from X-ray diffraction analysis on a microscopic level. The TEM results were all acquired using an FEI Tecnai G2 electron microscope, operating at $200 \mathrm{kV}$ on samples that were prepared by ion milling.

\section{RESULTS AND DISCUSSION}

\section{A. Phase formation and texture}

To study the phase formation sequence for a $30 \mathrm{~nm} \mathrm{Ni}$ film deposited on either a $\mathrm{Ge}(001)$ or $\mathrm{Ge}(111)$ oriented substrate, in situ XRD was performed. Figures 1(a) and 1(b) show in situ XRD spectra for both substrate orientations obtained using the standard diffraction geometry, but with the sample tilted in such a way that its normal is placed at an angle of $4^{\circ}$ with respect to the scattering plane to spare the detector from intense substrate diffraction peaks, a standard procedure on the $\mathrm{X} 20 \mathrm{C}$ beamline. Our results are very similar to those obtained by Gaudet et al. in $2006^{10}$ using the same experimental setup. According to these measurements, the reaction commences with the formation of a transient $\mathrm{Ni}$ rich germanide around $200^{\circ} \mathrm{C}$ characterized by a single diffraction peak around $37^{\circ}$ on $\mathrm{Ge}(001)$ or around $42^{\circ}$ on $\mathrm{Ge}(111)$. For both substrate orientations, NiGe forms as the final phase and is visible until it melts around $765^{\circ} \mathrm{C}$.

As no Ge diffraction peaks are expected within the $2 \theta$ window used for the in situ XRD measurements displayed in Figure 1, we also performed the same in situ XRD experiments without the $4^{\circ}$ tilt in $\chi$. The results are shown in Figures $1(\mathrm{c})$ and $1(\mathrm{~d})$ and reveal a very different picture of the phase formation sequence, especially on the $\mathrm{Ge}(111)$ substrate. In both cases, the diffraction peak resulting from the Ni-rich phase is much more pronounced. On the Ge(111) substrate, this phase does not disappear before the formation of NiGe, as suggested by the results from the tilted sample. This significantly different peak intensity depending on the tilt in $\chi$ indicates that the family of planes that contribute to this diffraction peak all have their plane normal pointing in 

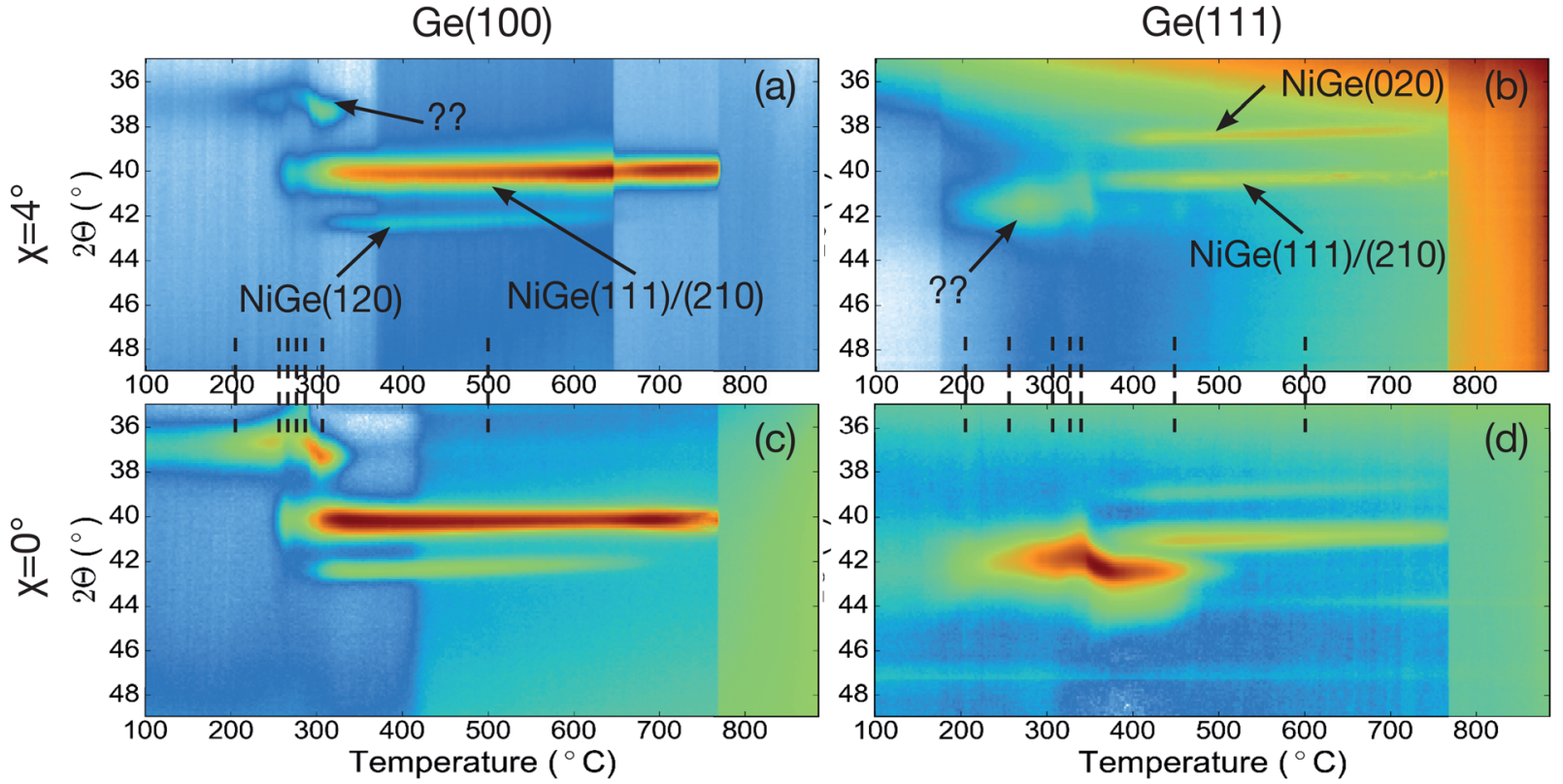

FIG. 1. In situ XRD spectra recorded during annealing of a $30 \mathrm{~nm}$ Ni film at $1{ }^{\circ} \mathrm{C} / \mathrm{s}$ on $\mathrm{Ge}(001)$ (left column, (a) and (c)) and Ge(111) (right column, (b) and (d)). The spectra in the top row were collected with the sample tilted over $4^{\circ}$ in $\chi$. The bottom row spectra were collected on samples having $0^{\circ}$ tilt. The dashed lines indicate the temperatures where quenches were made for detailed pole figure and TEM measurements.

the same direction. As such, this observation suggests a highly textured Ni-rich phase, possibly with an epitaxial alignment.

\section{Ni-rich phase identification}

As mentioned in the Introduction, no clear consensus exists in the literature concerning the nature of the Ni-rich germanide. In the most recent study performed by Gaudet et al. on single crystal Ge substrates, the transient phase was cautiously identified as monoclinic $\epsilon^{\prime}-\mathrm{Ni}_{5} \mathrm{Ge}_{3}{ }^{19}$ based on the weak diffraction peaks observed in the in situ XRD measurements visible in the top row of Figure 1 (marked with "??"). Indeed, the peak around $37^{\circ}$ on the $\mathrm{Ge}(001)$ substrate might be caused by either $\epsilon^{\prime}-\mathrm{Ni}_{5} \mathrm{Ge}_{3}$ (221), (312), or (021) and the peak around $42^{\circ}$ on the $\mathrm{Ge}(111)$ substrate by $\epsilon^{\prime}-\mathrm{Ni}_{5} \mathrm{Ge}_{3}$ (002). However, we recently observed that annealing mixed layers of $\mathrm{Ni}$ with $36 \%-48 \%$ Ge deposited on a $\mathrm{Ge}(001)$ substrate results in the formation of a metastable, hexagonal germanide. ${ }^{20}$ According to the bulk Ni-Ge binary phase diagram, ${ }^{21}$ three nonstoichiometric hexagonal nickel germanides exist above $300{ }^{\circ} \mathrm{C}$ in the Ge concentration range between $35 \%$ and $44 \%$, i.e., $\epsilon-\mathrm{Ni}_{5} \mathrm{Ge}_{3}, \mathrm{Ni}_{19} \mathrm{Ge}_{12}$, and $\mathrm{Ni}_{3} \mathrm{Ge}_{2}$. Due to the similar crystal structure and non-stoichiometric nature of these phases, they can be regarded as a single phase $\mathrm{e}^{20-22}$ which we will refer to as the " $\epsilon$-phase." As this phase is not expected to exist below its minimum stability temperature of $\pm 300^{\circ} \mathrm{C}$, it was not considered as a possible candidate for the transient phase in previous studies. However, the diffraction peaks around $37^{\circ}$ and $42^{\circ}$ in the in situ XRD measurements can perfectly be ascribed to the (101) and the (002) diffraction peaks of the $\epsilon$-phase.

In order to unambiguously identify this Ni-rich phase, we performed X-ray pole figure measurements on samples quenched at different temperatures (indicated by the vertical dashed lines in Figure 1) during the phase formation sequence. Figure 2 shows pole figures recorded on samples quenched at $240^{\circ} \mathrm{C}$ on $\mathrm{Ge}(001)$ (Figures 2(b), 2(d), 2(f)) and at $260^{\circ} \mathrm{C}$ on $\mathrm{Ge}(111)$ (Figures 2(a), 2(c), 2(e)), i.e., at temperatures where only the peak of the Ni-rich phase is visible in the in situ XRD measurements. The pole figures in the top row are obtained at $2 \theta=31.73^{\circ}(d=2.82 \AA)$, those in the second row at $2 \theta=44.62^{\circ}(d=2.03 \AA)$. These angles correspond to the Bragg diffraction condition for the $\epsilon$-phase (101) and (102) planes respectively. Clear diffraction spots can be observed at both angles and on both substrates, suggesting an epitaxially textured phase being present. We also observed diffraction spots on pole figures corresponding to the other diffracting planes of the $\epsilon$-phase within the $2 \theta$ window covered by the linear detector, while no diffraction features were observed on pole figures for other $2 \theta$ values. As the diffraction spots observed on the pole figures can indeed be fitted with an epitaxially textured $\epsilon$-phase (see Section III A 2 for more details on this epitaxy) and not with any of the other known nickel germanides, we are confident in identifying the observed Ni-rich phase as the hexagonal $\epsilon$-phase. Furthermore, high-resolution TEM diffraction experiments ${ }^{23}$ have confirmed the presence of $\epsilon$-phase grains in samples quenched at 240 and $280^{\circ} \mathrm{C}$ on $\mathrm{Ge}(001)$ and at 260,330 , and $345^{\circ} \mathrm{C}$ on $\mathrm{Ge}(111)$.

The formation of the hexagonal $\epsilon$-phase at a temperature below its thermodynamically stable temperature window (as defined in the bulk Ni-Ge phase diagram) is similar to what has been observed for a thin Ni film on single crystal silicon substrates. First, the formation of epitaxially textured $\theta$-nickel-silicide was observed when annealing mixed $\mathrm{Ni}(\mathrm{x} \% \mathrm{Si})$ films with $37 \leq x \leq 42 \%$ deposited on $\mathrm{Si}(001)$ and $\mathrm{Si}(111){ }^{24,25}$ Later, Gaudet et al. observed the formation of this phase during the reaction of pure $\mathrm{Ni}$ films on $\mathrm{Si}(001)$, where it forms as a transient phase with a fiber texture before 


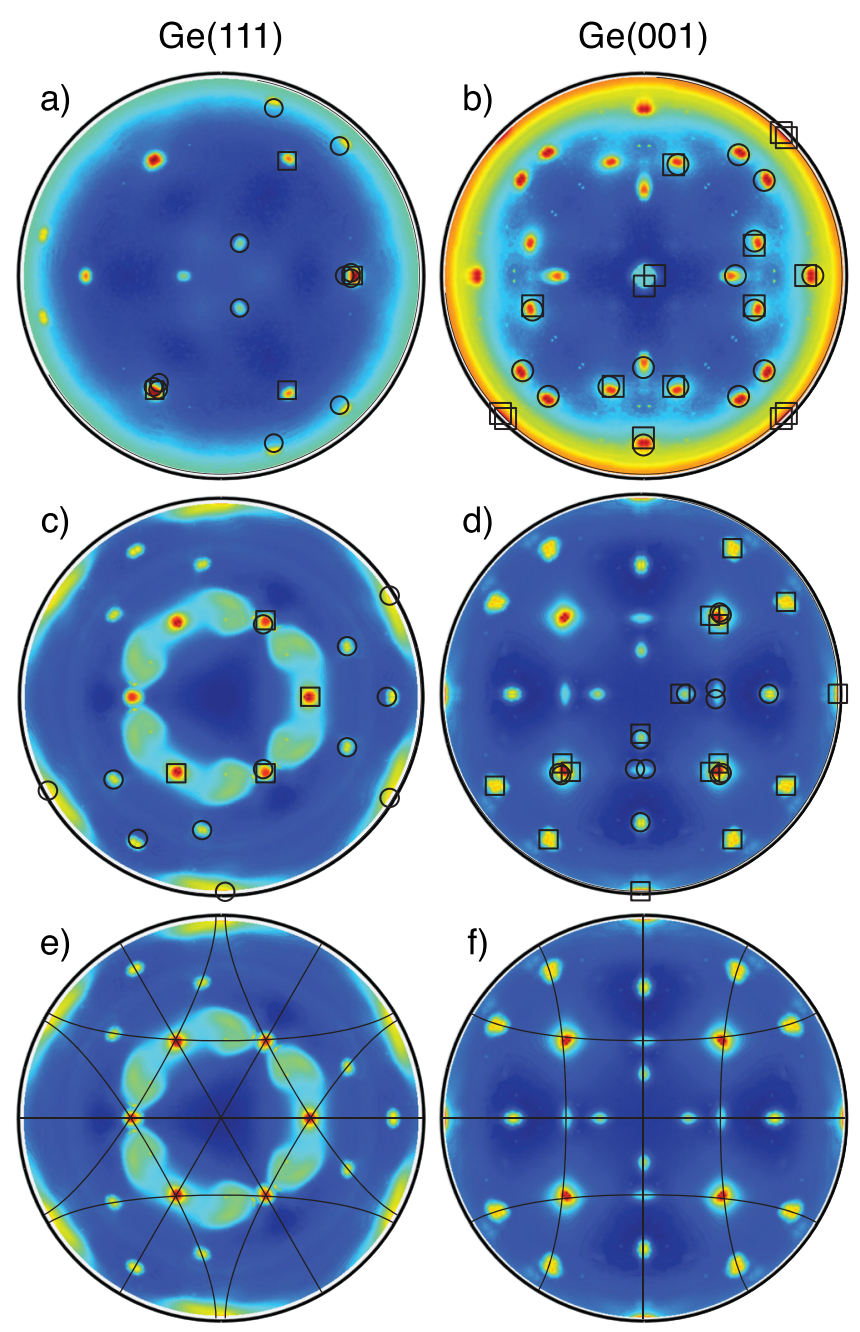

FIG. 2. Pole figures recorded at $2 \theta=31.73^{\circ}(d=2.82 \AA)$ (a), (b) and $2 \theta=44.62^{\circ}(d=2.03 \AA)$ (c)-(f) on both substrate types. The first diffraction angle corresponds to the $\epsilon(10 \overline{1} 1)$ plane, the second to $\epsilon(10 \overline{1} 2)$. On figures (a), (b), (c), and (d), the calculated locations of diffraction spots for the epitaxial components listed in Table I are overlaid on the pole figures. The symbol used for each component can be found in Table I. Calculated axiotaxy lines for the hypothetical $\epsilon(2 \overline{1} \overline{1} 0) / / \operatorname{Ge}\{110\}$ axiotaxy are overlaid on pole figures (e) and (f).

NiSi formation. ${ }^{26,27}$ On $\mathrm{Si}(111)$, it was only observed in the as-deposited film with an epitaxial texture. ${ }^{27}$ It is interesting to note that the $\theta$-phase in the $\mathrm{Ni}$-Si system and the $\epsilon$-phase in the Ni-Ge system have a similar hexagonal crystal structure (spacegroup $\mathrm{P}_{3} / \mathrm{mmc}$ ) and can both exist within a certain concentration window. ${ }^{20,24,28}$

\section{2. $\epsilon$-Phase texture}

Next to the identification of the $\epsilon$-phase, the pole figure measurements also allow for an investigation of its texture. On both substrate types, the analysis of the pole figures revealed the presence of two epitaxial texture components. A summary of the geometrical relations defining these components along with the symbol used in Figure 2 to mark the expected peak locations for these grain orientations is provided in Table I.

a. $\epsilon$-Phase on $\mathrm{Ge}(111)$. On $\mathrm{Ge}(111)$, the texture of the $\epsilon$-phase is characterized by two epitaxial components. The
TABLE I. Overview of the different $\epsilon$-phase epitaxial texture components that have been identified in $30 \mathrm{~nm} \mathrm{Ni}$ films on $\mathrm{Ge}(001)$ or $\mathrm{Ge}(111)$, quenched at 240 and $260^{\circ} \mathrm{C}$, respectively. For each component, a label and the symbol used to mark the locations of diffraction spots for that component in Figure 2 are given.

\begin{tabular}{|c|c|c|}
\hline \multicolumn{3}{|c|}{ Ge(111) substrate } \\
\hline Label & Relations & Symbol \\
\hline $\begin{array}{l}A_{111} \\
B_{111}\end{array}$ & $\begin{array}{c}\epsilon(0001) / / \mathrm{Ge}(111), \epsilon(2 \overline{1} 10) / / \mathrm{Ge}(01 \overline{1}) \\
\epsilon(02 \overline{2} 1) / / \mathrm{Ge}(111), \epsilon(2 \overline{1} \overline{1} 0) / / \mathrm{Ge}(01 \overline{1})\end{array}$ & $\begin{array}{l}\square \\
0\end{array}$ \\
\hline \multicolumn{3}{|c|}{$\mathrm{Ge}(001)$ substrate } \\
\hline Label & Relations & Symbol \\
\hline$A_{001}$ & $\epsilon(0001) / / \mathrm{Ge}(111), \epsilon(2 \overline{1} \overline{1} 0) / / \mathrm{Ge}(01 \overline{1}), \epsilon(01 \overline{1} 1) \sim / / \mathrm{Ge}(001)$ & $\square$ \\
\hline$B_{001}$ & $\epsilon(01 \overline{1} \overline{2}) / / \mathrm{Ge}(111), \epsilon(2 \overline{1} \overline{1} 0) / / \mathrm{Ge}(\overline{1} 10), \epsilon(01 \overline{1} 4) \sim / / \mathrm{Ge}(001)$ & $\bigcirc$ \\
\hline
\end{tabular}

highest intensity spots on the pole figures correspond to orientation $A_{111}$ (" $\square$ " symbols on Figures 2(a) and 2(c)), for which the hexagonal basal plane of the $\epsilon$-phase is parallel to the substrate, while the $\epsilon(2 \overline{1} 10)$ plane is parallel to a Ge $\{1 \overline{1} 0\}$ plane. This preferential alignment of the film's basal plane with the substrate (111) plane can be understood if we compare the positions of the Ge atoms in the $\mathrm{Ge}(111)$ and the $\epsilon(0001)$ planes. Figure 3(a) shows the topmost layer of atoms in the $\mathrm{Ge}(111)$ substrate. Half of the atoms are located slightly below the surface and are bonded to the Ge atoms below (white atoms in Figure 3(a)), while the other half lay at the surface (black atoms in Figure 3(a)) and have a dangling bond perpendicular to the Ge(111) interface. These topmost (black) Ge atoms are characterized by an interatomic distance of $4.00 \AA$ and display a hexagonal symmetry. In the $\epsilon(0001)$ plane (Figure $3(\mathrm{~b})$ ), the Ge atoms are located at the vertices of triangles, effectively creating the same hexagonal symmetry as the topmost Ge atoms in the

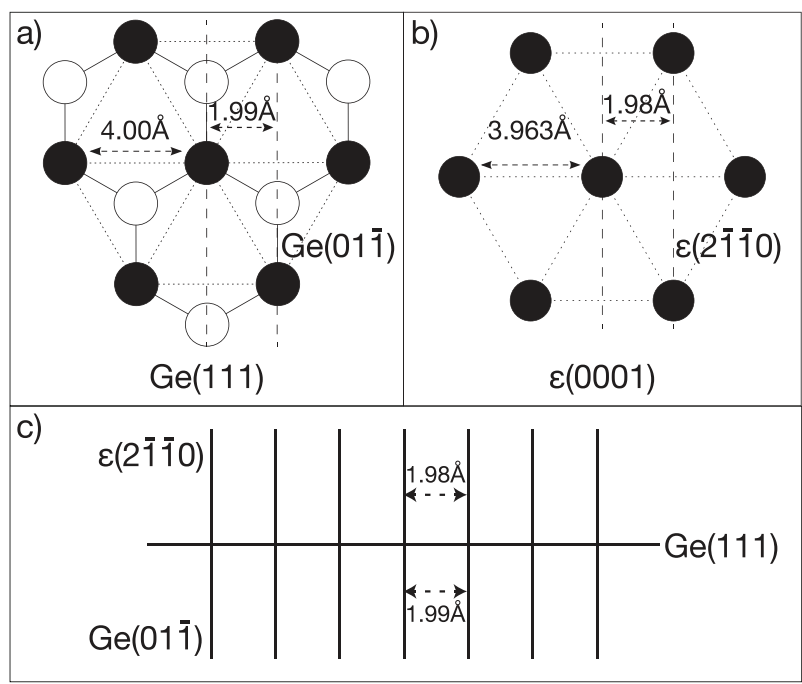

FIG. 3. (a) Ge atoms in the Ge(111) interface plane. Black ones are located at the interface and have a dangling bond. White ones are located slightly below the interface. (b) Ge atoms in the $\epsilon(0001)$ basal plane. (c) Alignment across the interface of the $\mathrm{Ge}(01 \overline{1})$ and the $\epsilon(2 \overline{1} \overline{10})$ planes, which is observed in both the $A_{111}$ and $B_{111}$ epitaxial components. 
Ge(111) plane. The Ge atoms in the $\epsilon(0001)$ plane have a dangling bond perpendicular to the plane of the triangles. Due to the large concentration window over which the $\epsilon$-phase can exist, the inter-atomic distance between the $\mathrm{Ge}$ atoms in the $\epsilon(0001)$ plane varies between 3.963 and $3.834 \AA$ for a $\mathrm{Ge}$ concentration of $35 \%$ and $44 \%$, respectively. ${ }^{21}$ As will be discussed in detail later, RBS measurements suggest that at the early stages of the reaction, the Ge concentration in the $\epsilon$-phase is around 35\%-37\%. At these Ge concentrations, the interatomic distance between the Ge atoms in the $\epsilon(0001)$ plane is about $3.963 \AA{ }^{21}$ This $\epsilon(0001)$ plane thus has a nearly perfect fit on the $\mathrm{Ge}(111)$ substrate (mismatch $\sim 0.9 \%$ ) which saturates the dangling bonds and leads to a low energy interface.

Next to the $A_{111}$ orientation which explains the highest intensity spots, there are some less intense spots visible on the pole figures for the $\epsilon$-phase formed on $\mathrm{Ge}(111)$ (see Figure 2(a), 2(c)) that cannot be explained by this orientation. These features can be explained by a second epitaxial texture component, labeled $B_{111}$, for which the $\epsilon(02 \overline{2} 1)$ plane is parallel to the $\mathrm{Ge}(111)$ interface and an $\epsilon\{2 \overline{1} \overline{1} 0\}$ is parallel to a $\operatorname{Ge}\{1 \overline{1} 0\}$ plane. When comparing the $B_{111}$ to the $A_{111}$ orientation discussed above, it is observed that both orientations have in common that an $\epsilon\{2 \overline{1} \overline{1} 0\}$ plane is parallel to a $\mathrm{Ge}\{1 \overline{1} 0\}$ plane. As the difference in d-spacing between an $\epsilon(2 \overline{1} 10)$ and a $\mathrm{Ge}\{220\}$ plane is only $0.33 \%$ ( $\epsilon$-phase at its lowest Ge concentration), this results in a (near) alignment of these planes across the interface. Such an alignment of lattice planes from film and substrate across the interface is also observed in the case of an axiotaxy texture. ${ }^{29}$ The geometry of this alignment is the same for both components and is sketched in Figure 3(c), from which it can be observed that both planes are aligned perpendicular to the interface. For the $A_{111}$ orientation, the alignment assures the nice overlap between the hexagonal arrangements of the Ge atoms in the $\mathrm{Ge}(111)$ and the $\epsilon(0001)$ planes at the interface. This can be seen in Figures 3(a) and 3(b), where the intersection of the interface plane with the $\mathrm{Ge}(01 \overline{1})$ (Figure 3(a)) and the $\epsilon(2 \overline{1} \overline{1} 0)$ planes (Figure 3(b)) is indicated by the vertical dashed lines. For the $B_{111}$ orientation, the alignment of an $\epsilon\{2 \overline{1} \overline{1} 0\}$ with a $\mathrm{Ge}\{1 \overline{1} 0\}$ plane also results in a reasonable overlap between the $\mathrm{Ge}$ atoms of the $\mathrm{Ge}(111)$ plane and the $\epsilon(02 \overline{2} 1)$ at the interface. Figure 4 shows a top view of this interface structure where the Ge atoms from the $\epsilon(02 \overline{2} 1)$ plane and the $\mathrm{Ge}(111)$ plane near the interface are indicated with open and filled circles, respectively.

The fact that the two observed epitaxial texture components $A_{111}$ and $B_{111}$ share the alignment of the aforementioned planes is visually clear if we plot the axiotaxy lines that would result from a hypothetical $\epsilon(2 \overline{1} \overline{1} 0) / / \operatorname{Ge}\{110\}$ axiotaxy on the pole figure (see Figure 2(e)). All the observed diffraction spots resulting from the $\epsilon$-phase are situated along these lines. In fact, the $A_{111}$ orientation can be transformed into the $B_{111}$ orientation through a rotation over $71.5^{\circ}$ around the normal to a $\mathrm{Ge}\{110\}$ plane. However, an axiotaxy texture component resulting from the observed alignment does not seem to be present here, as it is not visible in the pole figures in Figure 2. This suggests that the interfaces created by the two observed epitaxial grain

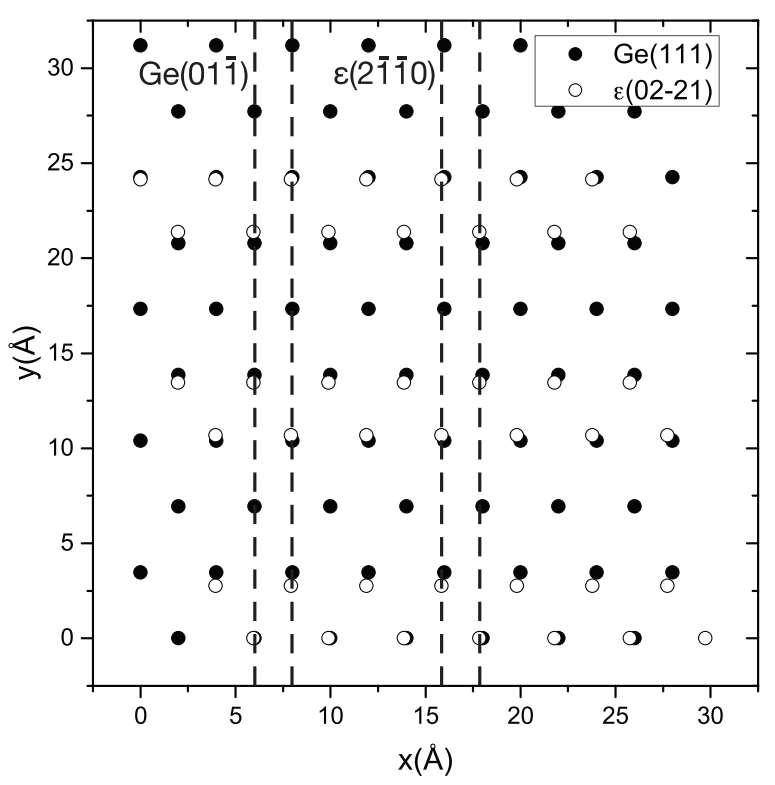

FIG. 4. Top view of the interface structure for the $B_{111}$ orientation. The Ge atoms in the $\epsilon(02 \overline{2} 1)$ and the $\mathrm{Ge}(111)$ planes at the interface are indicated with open and filled circles respectively. The intersections of the aligned $\mathrm{Ge}(01 \overline{1})$ and $\epsilon(2 \overline{1} \overline{1} 0)$ planes with the interface plane are indicated by the dashed lines.

orientations are very stable, as all grains are oriented according to either the $A_{111}$ or the $B_{111}$ epitaxial component.

b. $\epsilon$-Phase on $\mathrm{Ge}(001)$. Similar to the case on $\mathrm{Ge}(111)$, the texture of the $\epsilon$-phase formed from a $30 \mathrm{~nm} \mathrm{Ni}$ film on $\mathrm{Ge}(001)$ is characterized by two epitaxial components (see Table I). The $A_{001}$ orientation is identical to the $A_{111}$ orientation observed on the Ge(111) substrate. In this case however, the $\epsilon(0001)$ basal plane and a Ge$\{111\}$ plane are not parallel to the substrate-film interface, but they form an angle of $54.74^{\circ}$ with the interface. Based on the alignment of the $\epsilon(0001)$ and $\mathrm{Ge}\{111\}$ planes, one could also expect faceting to occur, a phenomenon where pyramidal structures are observed at the interface. The formation of such pyramidal structures would be driven by the formation of a matching interface between $\epsilon(0001)$ and $\mathrm{Ge}\{111\}$ as discussed in Figure 3 at the sides of the pyramids. As will be discussed in more detail in Section III B, such a pronounced faceting was not observed here. A side-on view of the Ge atoms in the vicinity of the interface for the $A_{001}$ orientation is plotted in Figure 5. The Ge $\{111\}$ and $\epsilon$-phase $\{0001\}$ planes are shown, intersecting the interface. Because the Ge atoms in these planes have nearly identical interatomic spacing, dangling bonds at the interface will be saturated wherever these planes meet. From Figure 5, it is clear that about one in three of the $\mathrm{Ge}\{111\}$ planes meet an $\epsilon\{0001\}$ plane at the interface. This alignment is very similar to what has been observed previously for the $\theta$-nickel-silicide phase formed from a $\mathrm{Ni}(40 \% \mathrm{Si})$ film deposited on $\mathrm{Si}(001){ }^{24}$

Similar to what was observed on $\mathrm{Ge}(111)$, both observed epitaxies on $\mathrm{Ge}(001)$ are characterized by the alignment of an $\epsilon\{2 \overline{1} \overline{1} 0\}$ with a Ge$\{110\}$ plane, both perpendicular to the interface in both orientations. In Figure 2(f), this shared 


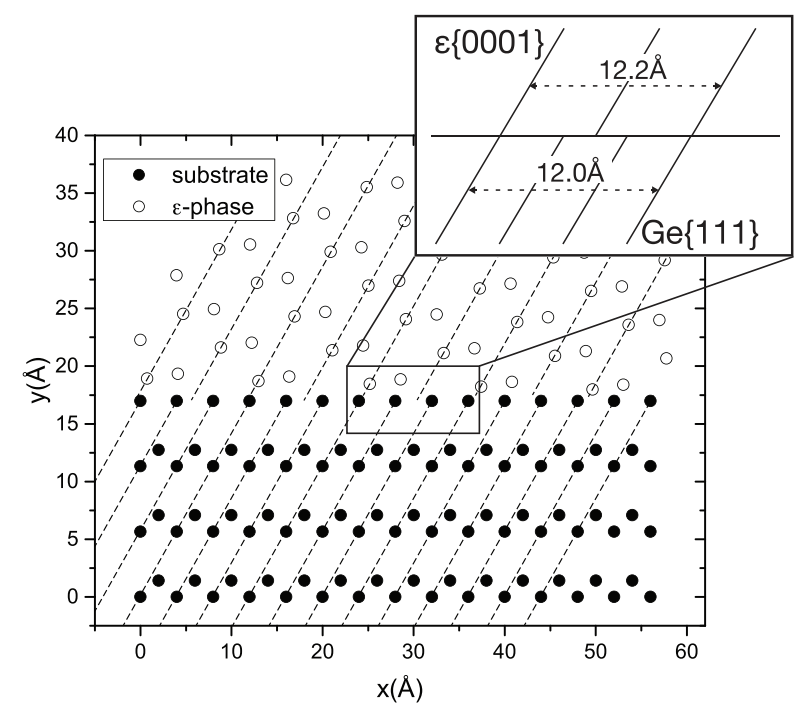

FIG. 5. Cross-sectional view of the alignment across the interface of the $\epsilon(0001)$ and $\mathrm{Ge}(111)$ planes for the $A_{001}$ orientation. The view direction is perpendicular to the $\mathrm{Ge}(0 \overline{1} 1)$ plane. Ge atoms in the $\epsilon$-phase and the Ge substrate are plotted using open and filled circles respectively.

alignment is visualized by overlaying the axiotaxy lines for a hypothetical $\epsilon(2 \overline{1} \overline{1} 0) / / \operatorname{Ge}\{110\}$ axiotaxy on the pole figure. An actual axiotaxy texture component resulting from the alignment was not observed.

\section{Phase formation sequence}

As the information regarding the phase formation sequence gained from the in situ XRD results is influenced by the texture of the different phases, a more detailed investigation was done by performing pole figure measurements on samples quenched at different temperatures during the heat treatment on both substrate types. The temperatures of the different quenches are indicated on the in situ XRD spectra in Figure 1. In Figure 6, we show pole figures collected on the different quenched samples at $2 \theta=44.5^{\circ}(d=2.03 \AA)$, as one can expect to see diffraction features of planes from the three phases that occur during the phase formation sequence-Ni(111) $(d=2.034 \AA), \quad \epsilon(10 \overline{1} 2) \quad(d=2.028 \AA)$, and $\operatorname{NiGe}(211)(d=2.049 \AA)$ - at this diffraction angle. It must be noted that a contribution from the $\operatorname{Ge}\{220\}$ ( $d=2.00 \AA$ ) substrate planes is also expected, resulting in intense diffraction peaks on the displayed pole figures at $\chi=45^{\circ}, \phi=45^{\circ}, 135^{\circ}, 225^{\circ}, 315^{\circ}$ and at $\chi=90^{\circ}, \phi=0^{\circ}$, $90^{\circ}, 180^{\circ}, 270^{\circ}$ for the $\mathrm{Ge}(001)$ substrate. For the $\mathrm{Ge}(111)$ substrate, $\operatorname{Ge}\{220\}$ contributions are visible at $\chi=35.26^{\circ}$, $\phi=0^{\circ}, 120^{\circ}, 240^{\circ}$. In Figure 6 , one of each set of these peaks is indicated on the as deposited pole figure for both substrate types.

Both on $\mathrm{Ge}(001)$ and on $\mathrm{Ge}(111)$, the phase formation sequence was determined by combining the in situ XRD results with the pole figure data collected at the different quenching temperatures. At each temperature, we identified the phases present in the system through the characteristic set of diffraction features on the pole figure for each phase. For the $\epsilon$-phase, these characteristic features resulting from diffraction of the $\epsilon(10 \overline{1} 2)$ plane were discussed in Section
III A 2 (see Figure 2). For NiGe, the characteristic diffraction features can be observed in the pole figures quenched at the highest temperature on both substrate types, i.e., $500^{\circ} \mathrm{C}$ on $\mathrm{Ge}(001)$ and $600{ }^{\circ} \mathrm{C}$ on $\mathrm{Ge}(111)$, as only NiGe is present at those temperatures. As our pole figure measurements reveal the same texture for the NiGe phase as observed and discussed by Gaudet et al., the reader is referred to Ref. 10 for more details.

Summaries of the phases that are present according to the pole figure and in situ XRD data at the different quenching temperatures during a ramp anneal at $3{ }^{\circ} \mathrm{C} / \mathrm{s}$ are provided in Tables II and III for the reaction on $\mathrm{Ge}(001)$ and $\mathrm{Ge}(111)$, respectively. A more detailed discussion on the formation sequence observed on both substrate orientations is given below.

a. $30 \mathrm{~nm} \mathrm{Ni}$ on $\mathrm{Ge}(001)$. On $\mathrm{Ge}(001)$, no diffraction features resulting from the deposited Ni layer were observed on the pole figure acquired on the as deposited sample, while the $\mathrm{Ni}(111)$ and (002) peaks were observed in an in situ XRD measurement at a higher $2 \theta$ window. ${ }^{23}$ This indicates a polycrystalline $\mathrm{Ni}$ film with a random texture being present after deposition. The Ni peaks remain visible in the in situ XRD data up until a temperature of $280^{\circ} \mathrm{C}$.

The most important observation from the pole figure acquired on the as deposited sample is the presence of (weak) diffraction spots characteristic for the $\epsilon$-phase at $\chi=78.4^{\circ}$ (see top left pole figure of Figure 6), indicating that this phase already forms during deposition of the $\mathrm{Ni}$ film. This is similar to what has been observed by Gaudet et al. in as-deposited $\mathrm{Ni}$ films on $\mathrm{Si}(111)$, where a very thin epitaxially aligned $\theta$-nickel-silicide layer is present at the interface. $^{27}$ In contrast to the $\theta$ phase observed for asdeposited Ni films on $\mathrm{Si}(111)$, which transforms immediately into $\delta-\mathrm{Ni}_{2} \mathrm{Si}$ upon heating, the $\epsilon$-phase here remains present as the sole phase until it is consumed by NiGe. In our recent study on phase formation in co-deposited $\mathrm{Ni}(\mathrm{x} \% \mathrm{Ge})$ films on $\mathrm{SiO}_{2}$ and $\mathrm{Ge}(001)$ substrates, ${ }^{20}$ we also observed the metastable formation of this $\epsilon$-phase in films with a Ge concentration between $36 \%$ and $48 \%$. Furthermore, in the Ge concentration window between $36 \%$ and $44 \%$, the $\epsilon$-phase was observed to have formed during deposition of the mixed $\mathrm{Ni}(\mathrm{x} \% \mathrm{Ge})$ layer on both $\mathrm{SiO}_{2}$ and $\mathrm{Ge}(001)$ substrates. As it is generally accepted that a very thin intermixed Ni-Ge (or $\mathrm{Ni}$-Si) layer forms during deposition of $\mathrm{Ni}$ on a $\mathrm{Ge}$ (or $\mathrm{Si}$ ) substrate, the as-deposited $\epsilon$-phase nucleation observed in this study can be intuitively understood from the previous results if we assume that the thin intermixed $\mathrm{Ni}-\mathrm{Ge}$ film is characterized by a Ge concentration between $36 \%$ and $44 \%$. However, the exact physical reasons as to why the $\epsilon$-phase nucleates that easily under these conditions are still an open question.

On the pole figure for the sample quenched at $240{ }^{\circ} \mathrm{C}$, $\mathrm{NiGe}\{211\}$ diffraction spots become weakly visible near the edge (see Figure 6). The formation of this phase is also visible in the in situ XRD measurements through the emergence of the $\mathrm{NiGe}(111) /(210)$ diffraction peak around the same temperature. The $\epsilon$-phase and $\mathrm{NiGe}$ both remain present up to a temperature of $335^{\circ} \mathrm{C}$, when the $\epsilon$-phase is completely 

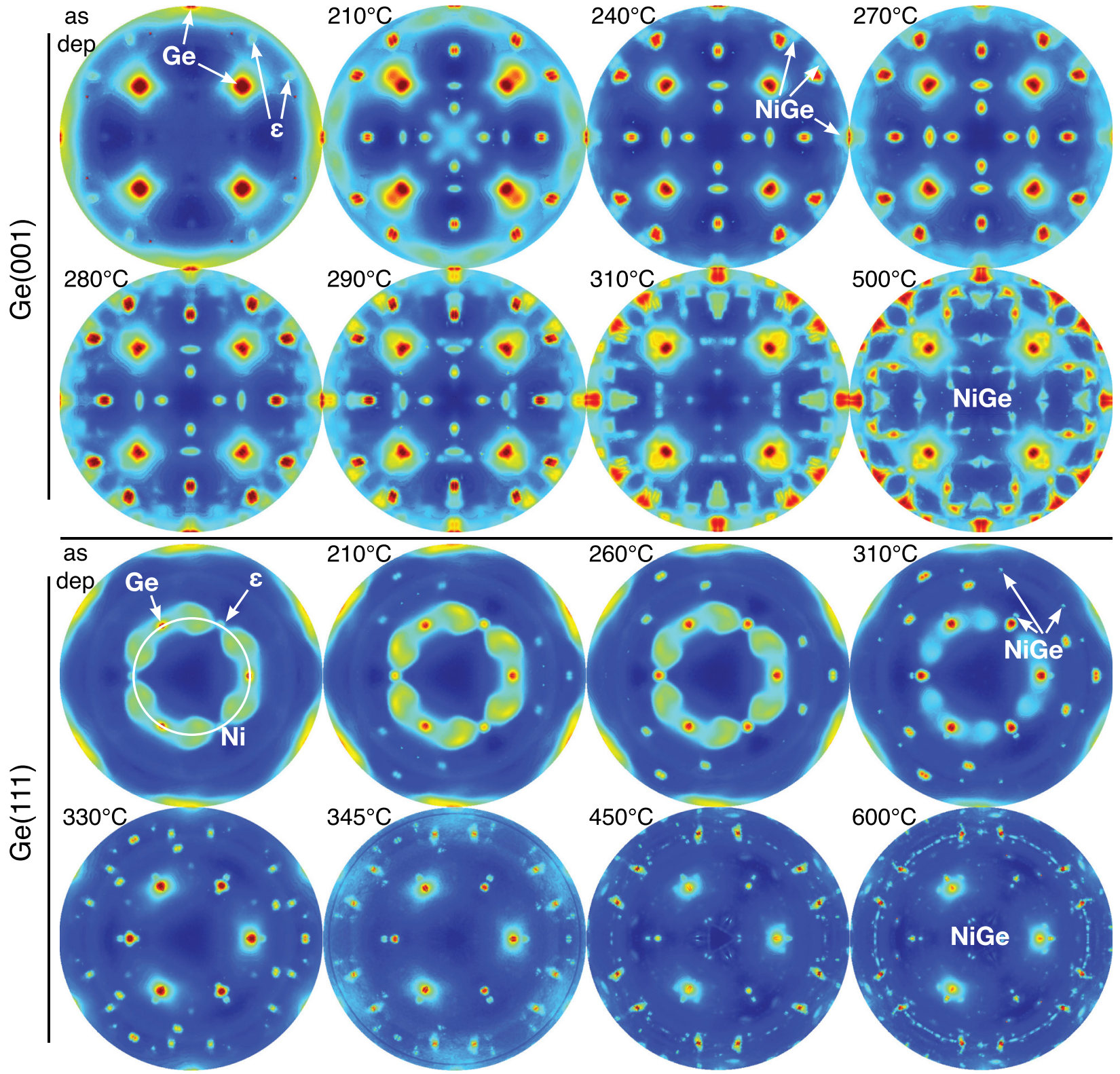

FIG. 6. Selection of pole figures $\left(2 \theta=44.5^{\circ} ; d=2.03 \AA\right)$ recorded on samples quenched at different temperatures on both substrate orientations.

consumed by the growing NiGe phase which then remains the stable end phase until it melts around $780^{\circ} \mathrm{C}$. According to the pole figure recorded on the sample quenched at $500^{\circ} \mathrm{C}$ (where NiGe is the only phase present), the NiGe phase is characterized by a complex texture. As was mentioned

TABLE II. Identified phases in the pole figures recorded on samples quenched at the temperatures indicated in the first column on $\mathrm{Ge}(001)$.

\begin{tabular}{lc}
\hline \hline Temperature $\left({ }^{\circ} \mathrm{C}\right)$ & Identified phases \\
\hline As deposited & $\mathrm{Ni}, \epsilon$-phase \\
210 & $\mathrm{Ni}, \epsilon$-phase \\
240 & $\mathrm{Ni}, \epsilon$-phase, $\mathrm{NiGe}$ \\
270 & $\mathrm{Ni}, \epsilon$-phase, $\mathrm{NiGe}$ \\
280 & $\mathrm{Ni}, \epsilon$-phase, $\mathrm{NiGe}$ \\
290 & $\epsilon$-phase, $\mathrm{NiGe}$ \\
310 & $\epsilon$-phase, $\mathrm{NiGe}$ \\
500 & $\mathrm{NiGe}$ \\
\hline \hline
\end{tabular}

before, the texture of this phase on $\mathrm{Ge}(001)$ was studied in detail by Gaudet et al. ${ }^{10}$ and was found to be a combination of five different epitaxial components and three very weak axiotaxy components for which either the NiGe(121), (220), or (211) plane is aligned with a $\mathrm{Ge}\{110\}$ plane.

TABLE III. Identified phases in the pole figures recorded on samples quenched at the temperatures indicated in the first column on $\mathrm{Ge}(111)$.

\begin{tabular}{lc}
\hline \hline Temperature $\left({ }^{\circ} \mathrm{C}\right)$ & Identified phases \\
\hline As deposited & $\mathrm{Ni}, \epsilon$-phase \\
210 & $\mathrm{Ni}, \epsilon$-phase \\
260 & $\mathrm{Ni}, \epsilon$-phase \\
310 & $\mathrm{Ni}, \epsilon$-phase, $\mathrm{NiGe}$ \\
330 & $\epsilon$-phase, $\mathrm{NiGe}$ \\
345 & $\epsilon$-phase, $\mathrm{NiGe}$ \\
450 & $\epsilon$-phase, $\mathrm{NiGe}$ \\
600 & $\mathrm{NiGe}$ \\
\hline
\end{tabular}


b. $30 \mathrm{~nm} \mathrm{Ni}$ on $\mathrm{Ge}(111)$. On Ge(111), no diffraction peaks from the as-deposited $\mathrm{Ni}$ film were observed at the expected diffraction angles for the $\mathrm{Ni}(111)$ and $(002)$ peaks (at $2 \theta=52.4^{\circ}$ and $61.3^{\circ}$ ), ${ }^{23}$ which is indicative of a textured Ni film after deposition. Indeed, the pole figure collected on the as-deposited sample suggests that the Ni film is deposited with a broad $\mathrm{Ni}(110)$ fiber texture (i.e., the $\mathrm{Ni}(110)$ plane is parallel to the interface), which is characterized by the broad ring visible around $\chi=35^{\circ}$ (see Figure 6, pole figure on asdeposited $\mathrm{Ge}(111)$ sample), resulting from the $\mathrm{Ni}\{111\}$ planes that have a $35.26^{\circ}$ angle with respect to the $\mathrm{Ni}(110)$ plane. Furthermore, it can be observed that the diffracted intensity is not uniformly distributed around the fiber ring, but is concentrated in broad lobe-like features. Deeper analysis suggests that the rotation of the different $\mathrm{Ni}$ grains around the substrate normal is not uniformly distributed, but that there is a tendency for the $\mathrm{Ni}$ grains to align their $(1 \overline{1} 1)$ or

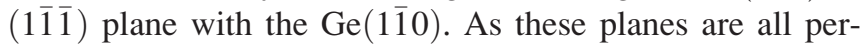
pendicular to the $\mathrm{Ge}(111)$ interface plane and the difference in $d$-spacing between these $\mathrm{Ni}$ planes and the $\mathrm{Ge}(2 \overline{2} 0)$ plane is only $0.19 \%\left(d_{N i\{1 \overline{1} 1\}}=1.992 \AA ; d_{G e\{2 \overline{2} 0\}}=1.988 \AA\right)$, this should indeed result in a better match at the interface.

Next to the textured Ni film, the pole figure collected on the as-deposited sample (see Figure 6) again shows the presence of the $\epsilon$-phase, similar to what was observed on $\mathrm{Ge}(001)$. The presence of this phase is evidenced by the faint diffraction spots around $\chi=35^{\circ}$, characteristic for the $A_{111}$ epitaxy (see Figure 2(c)). Thus, the initial $\epsilon$-phase nuclei that form during the deposition of the Ni film have their (0001) basal plane parallel to the Ge(111) interface plane, resulting in the excellent match at the interface as discussed above (see Figure 3). The $\epsilon$-phase then grows at the expense of $\mathrm{Ni}$ as the temperature is ramped. On the $210^{\circ} \mathrm{C}$ pole figure, one can observe diffraction features of the $B_{111}$ epitaxy as well. However, because the absence of an $\epsilon(02 \overline{2} 1)$ diffraction peak in the in situ XRD measurements and the limited number of temperatures where pole figures were collected, it is hard to pinpoint the exact temperature at which grains with this orientation start to form.

Weak diffraction spots characteristic for the NiGe phase are first observed in the pole figure recorded on the sample quenched at $310^{\circ} \mathrm{C}$. In the in situ XRD measurements, the formation of this phase is characterized by the $\mathrm{NiGe}(111) /$ (210) and $\mathrm{NiGe}(020)$ peak at $2 \theta=41^{\circ}$ and $2 \theta=39^{\circ}$, respectively. Up until a temperature of $\sim 500^{\circ} \mathrm{C}$, both $\mathrm{NiGe}$ and the $\epsilon$-phase are visible both in the in situ XRD and in the pole figure measurements. At that point, the $\epsilon$-phase has been completely consumed by the growing $\mathrm{NiGe}$, which remains present until it melts around $780^{\circ} \mathrm{C}$. Gaudet et al. discussed in detail the texture of this NiGe phase formed on $\mathrm{Ge}(111)$, which is a combination of two strong fiber components (either a NiGe $\{010\}$ or $\{101\}$ plane parallel to the interface), no less than eight epitaxial components and the same, weak axiotaxy components that were also observed on $\mathrm{Ge}(001) .{ }^{10}$

Compared to the results on the $\mathrm{Ge}(001)$ substrate discussed above, the temperature window over which the $\epsilon$-phase is present is extended by more than $150^{\circ} \mathrm{C}$. As the interface with the lowest lattice mismatch between the $\epsilon$-phase and the Ge substrate is obtained for the $A_{111}$ orientation on Ge(111), this will likely result in the lowest interface energy. The extended stability window of the $\epsilon$-phase on the Ge(111) substrate thus suggests that the interface energy plays an important role in the stabilization of this phase. The low energy interface makes the nucleation of the NiGe phase more difficult, which leads to the elevated NiGe formation temperature on the $\mathrm{Ge}(111)$ substrate. This is similar to what has been observed for $\mathrm{CoGe}_{2}$ formation on $\mathrm{Ge}(111)$, on which the epitaxial orientation of the preceding $\mathrm{Co}_{5} \mathrm{Ge}_{7}$ phase results in an elevated $\mathrm{CoGe}_{2}$ formation temperature compared to a $\mathrm{Ge}(001)$ substrate, where the epitaxial $\mathrm{Co}_{5} \mathrm{Ge}_{7}$ orientation is less pronounced. ${ }^{15}$

\section{B. Film structure}

Figure 7 shows three TEM cross-section of the interface on samples that were used for the pole figure measurements quenched at $280^{\circ} \mathrm{C}$ on $\mathrm{Ge}(001)$ (Figure $7(\mathrm{a})$ ) and $330^{\circ} \mathrm{C}$ on $\mathrm{Ge}(111)$ (Figure 7(b)), as well as on the as-deposited $\mathrm{Ge}(111)$ sample (Figure 7(c)). On both substrates, the layered growth typical for solid-phase silicidation/germanidation reactions $^{9,30,31}$ is visible. Taking into account the phases identified based on the X-ray pole figure measurements, a corroborative identification was performed using an HR-TEM Fourier
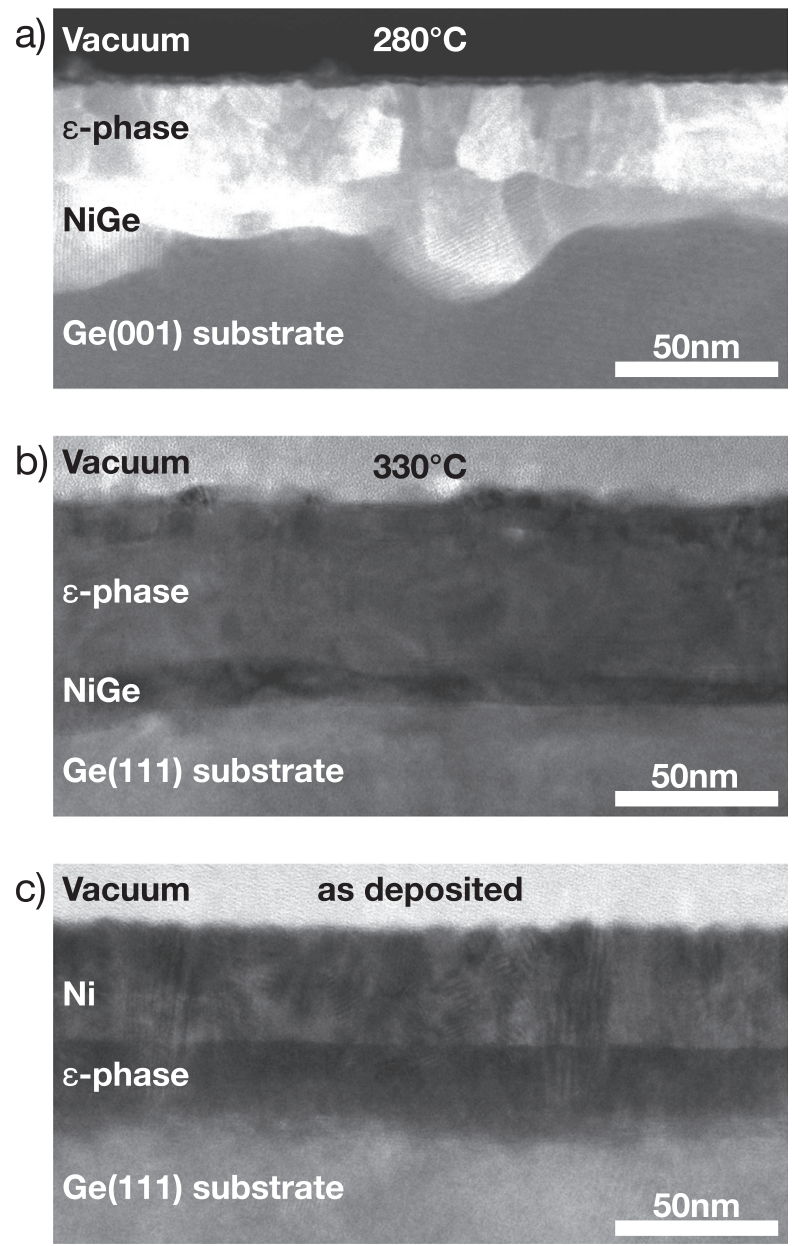

FIG. 7. Cross-section HAADF-STEM (a) and BF-TEM (b) and (c) images for Ni films deposited on both $\mathrm{Ge}(001)$ (a) and (111) (b), (c) substrates and quenched at different temperatures (indicated on the figures). 
transform study. For all quenches, the same phases were identified using these two techniques.

For the sample on $\mathrm{Ge}(001)$ quenched at $280^{\circ} \mathrm{C}$, two distinct layers are clearly visible (Figure 7(a)). The two phases were identified as the $\epsilon$-phase and NiGe, which corresponds to what is expected from the XRD results. Indeed, when looking at the in situ XRD spectra on Ge(001) (Figure 1(c)), both the $\epsilon(10 \overline{1} 1)$ and $\mathrm{NiGe}(111) /(210)$ peaks are visible at that temperature. At this stage of the reaction, the NiGe phase is growing beneath the preceding $\epsilon$-phase by consuming it. The HAADF-STEM cross-section also reveals a quite rough interface between the NiGe layer and the Ge(001) substrate. A similarly rough interface was observed by Nemouchi et al. ${ }^{9}$ for a NiGe layer formed by an isothermal anneal at $180^{\circ} \mathrm{C}$ during $110 \mathrm{~min}$ on an amorphous Ge substrate, but an explanation for this interface roughening was not provided. In our case, we believe that the texture of the preceding $\epsilon$-phase can at least partly explain this rough interface. The alignment and the high quality match between the $\epsilon(0001)$ and $\mathrm{Ge}(111)$ planes, which form an angle of $54.74^{\circ}$ with the interface, can result in some degree of faceting through the formation of pyramid-like structures at the interface, much like what is observed for epitaxial $\mathrm{NiSi}_{2}$ on $\mathrm{Si}(001){ }^{32} \mathrm{We}$ also observed a similar faceting with the $\theta$-nickel-silicide formed from a $\mathrm{Ni}(40 \% \mathrm{Si})$ film on $\mathrm{Si}(001)$, which displays a similar texture as the $\epsilon$-phase. ${ }^{24,33}$ However, cross-sectional images on a sample quenched at lower temperatures on $\mathrm{Ge}(001)$ are needed to support this hypothesis.

The sample quenched at $330^{\circ} \mathrm{C}$ on the $\mathrm{Ge}(111)$ substrate shows a much flatter interface. Again, both a thin, growing $\mathrm{NiGe}$ can be observed that consumes the $\epsilon$-phase layer above. Since on this substrate orientation the $\epsilon$-phase(0001) has a nearly perfect match with the Ge(111) plane which is now parallel to the interface, no faceting is expected to occur. This results in a flat $\epsilon$-phase/Ge interface, which we have observed in BF-TEM cross-sections on samples quenched at lower temperatures. ${ }^{23}$ The NiGe phase can then nucleate at a flat interface, resulting in the observed, flat $\mathrm{NiGe} / \mathrm{Ge}(111)$ interface.

In Figure 7(c), we included a BF-TEM cross-section of an as-deposited sample on $\mathrm{Ge}(111)$. The pure $\mathrm{Ni}$ layer is clearly visible, together with a $\sim 20 \mathrm{~nm}$ thick layer containing both $\mathrm{Ni}$ and $\mathrm{Ge}$ in contact with the Ge(111) substrate. The formation of an intermixed layer with such a thickness is quite surprising, as for metals deposited on $\mathrm{Si}$, the intermixed interface layer is typically only a few nanometers thick. ${ }^{34}$ In this layer, several $\epsilon$-phase grains were detected using high resolution TEM imaging, all at the interface with the Ge substrate. The fact that we only observed very weak $\epsilon$-phase diffraction features in the pole figure collected on this sample (see Figure 6) suggests that a large fraction of this layer is still amorphous.

\section{Kinetics}

Details on the kinetics during the phase formation sequence were investigated using in situ RBS, a technique that yields quantitative elemental depth maps as a function of temperature. These maps are displayed as a contour plot by merging the successive RBS spectra collected during the ramp anneal in Figures 8(a) and 8(b) for the reaction between a $60 \mathrm{~nm}$ Ni film and a $\mathrm{Ge}(001)$ or (111) substrate, respectively. To allow for a good comparison between both substrates, the temperature axes are drawn with the same scale, although no RBS spectra were collected on the (001) substrate above $340^{\circ} \mathrm{C}$ because the reaction had already finished. The scattering energies for $\mathrm{Ni}$ and $\mathrm{Ge}$ atoms located at the sample surface are marked along with an indication of the expected backscattering energy for a $\mathrm{Ni}$ or $\mathrm{Ge}$ atom located at $60 \mathrm{~nm}$ below the surface (i.e., the thickness of the deposited Ni film). Before these results are discussed, two important points have to be considered. First, due to the smaller mass of $\mathrm{Ni}$ compared to $\mathrm{Ge}$, the signals of $\mathrm{Ni}$ and $\mathrm{Ge}$ overlap. As the Ni surface energy is only slightly smaller than that of $\mathrm{Ge}$, the Ni peak is superimposed on the plateau resulting from the "infinitely" thick Ge substrate. Therefore, phase transformations are harder to distinguish from these raw data compared to a case where the signals are separated (e.g., for $\mathrm{Ni}$ on $\mathrm{Si}^{16,18,35}$ ) and the individual spectra are much more difficult to analyse. Second, the ramp rate used in these experiments $\left(2^{\circ} \mathrm{C} / \mathrm{min}\right)$ is much slower than the one used for the in situ XRD measurements $\left(1^{\circ} \mathrm{C} / \mathrm{s}\right)$. Therefore, formation temperatures obtained with in situ RBS are not directly comparable to those obtained from in situ XRD due to the different thermal budget applied at a specific temperature.

From the RBS maps in Figure 8, it is clear that the reaction on the $\mathrm{Ge}(001)$ substrate proceeds much faster than on
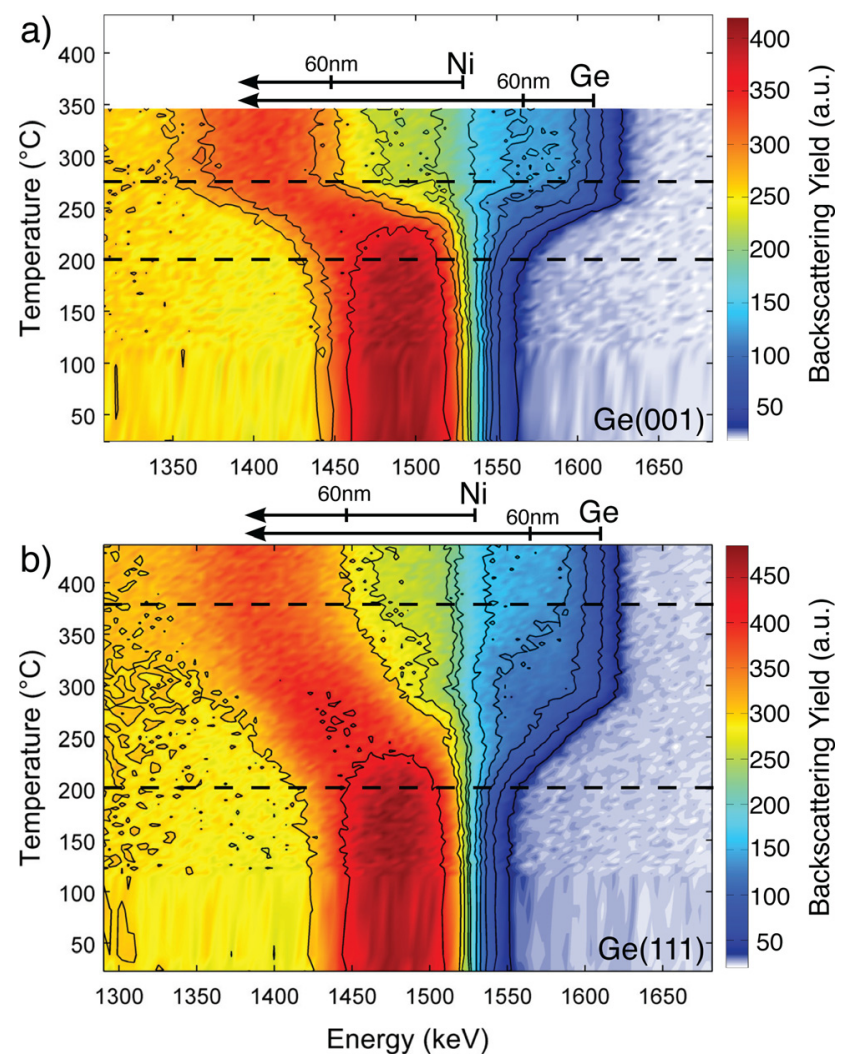

FIG. 8. In situ RBS measurements of a $60 \mathrm{~nm} \mathrm{Ni}$ film deposited on (a) $\mathrm{Ge}(001)$ and (b) $\mathrm{Ge}(111)$, performed during an anneal at $2{ }^{\circ} \mathrm{C} / \mathrm{min}$. An indicative depth scale is provided for both $\mathrm{Ni}$ and $\mathrm{Ge}$. 
the $\mathrm{Ge}(111)$ substrate. In both cases, the reaction sets off around $200^{\circ} \mathrm{C}$, indicated by the concentration drop in the $\mathrm{Ni}$ peak and the bending of the contour lines of both the Ni peak and the Ge shoulder. On $\mathrm{Ge}(001)$, the reaction seems to be completed around $280^{\circ} \mathrm{C}$, while on the $\mathrm{Ge}(111)$ substrate, the bending of the contour lines only stops around $350-400^{\circ} \mathrm{C}$. This confirms the XRD-based observations discussed above, where a difference of more than $150^{\circ} \mathrm{C}$ was observed between both substrate orientations for the temperature at which $\mathrm{NiGe}$ has completely consumed the $\epsilon$-phase. We also note that a previous study conducted by Comrie et al. showed that $\mathrm{Ni}$ is the sole diffusing species during formation of the Ni-rich phase. During the growth of NiGe, the early stages are dominated by $\mathrm{Ge}$ diffusion, while $\mathrm{Ni}$ becomes the dominating diffusing species at the later stages of the growth. ${ }^{36}$

In order to study the kinetics of the solid-phase reaction from the in situ RBS results, a 3-layer model was fitted to all individual RBS spectra using an artificial neural network (ANN), a technique which allows for the quasi-instantaneous analysis of a huge set of RBS spectra without deteriorating the quantitative accuracy. ${ }^{37}$ The output of the ANN analysis was subsequently refined using the NDF code. ${ }^{38}$ Based on the phases that were identified by XRD, as discussed above, the spectra were fitted using a pure Ni layer, a Ni-rich $\mathrm{Ni}_{x} \mathrm{Ge}_{y}$ layer with a variable $\mathrm{Ni}: \mathrm{Ge}$ concentration (as a model for the $\epsilon$-phase), and a NiGe layer with a fixed $\mathrm{Ni}$ :Ge ratio of $1: 1$. The fits were validated by comparing simulated RBS spectra generated by using the results of the ANN with the raw RBS spectra at each temperature.

Figure 9 shows the thickness evolution of the various fitted phases as a function of temperature (using the same temperature scale on the x-axis) on both the $\mathrm{Ge}(001)$ substrate (a) and Ge(111) substrate (b). This thickness is expressed in the number of $\mathrm{Ni}$ atoms in each phase $\left(\mathrm{at} / \mathrm{cm}^{2}\right)$ as this allows us to normalize the layer thicknesses in such a way that the sum of the individual layer thicknesses (i.e., the total Ni content in the entire system) is constant. In this way, the proportion of the formed layers becomes clear and the consistency of the values is validated, as the total sum of $\mathrm{Ni}$ atoms across all layers should remain constant. As can be observed in both figures, there is quite some noise on the fitted thicknesses, in particular, for low values $\left(<100 \mathrm{at} / \mathrm{cm}^{2}\right)$. This is due to the overlapping Ni and Ge signals in the RBS spectra, which impedes the fitting procedure when the layers are very thin (i.e., at the initial formation stage). Therefore, absolute values of the fitted thickness below $150 \mathrm{at} / \mathrm{cm}^{2}$ should not be given too much attention. Nevertheless, these fitted thickness evolutions give us some valuable qualitative insights on the phase formation sequence.

On both substrate orientations, the growth of the $\epsilon$-phase sets off around $200^{\circ} \mathrm{C}$. However, from the in situ XRD results, we observed the presence of the $\epsilon$-phase in the asdeposited films. This suggests that at lower temperatures there is only limited growth of this phase. As the $\epsilon$-phase layer is thin at these temperatures compared to the total thickness of the deposited film ( $60 \mathrm{~nm}$ for the RBS samples), it is hard to reliably fit its thickness in the RBS spectra. A possible explanation for this limited growth below $200^{\circ} \mathrm{C}$
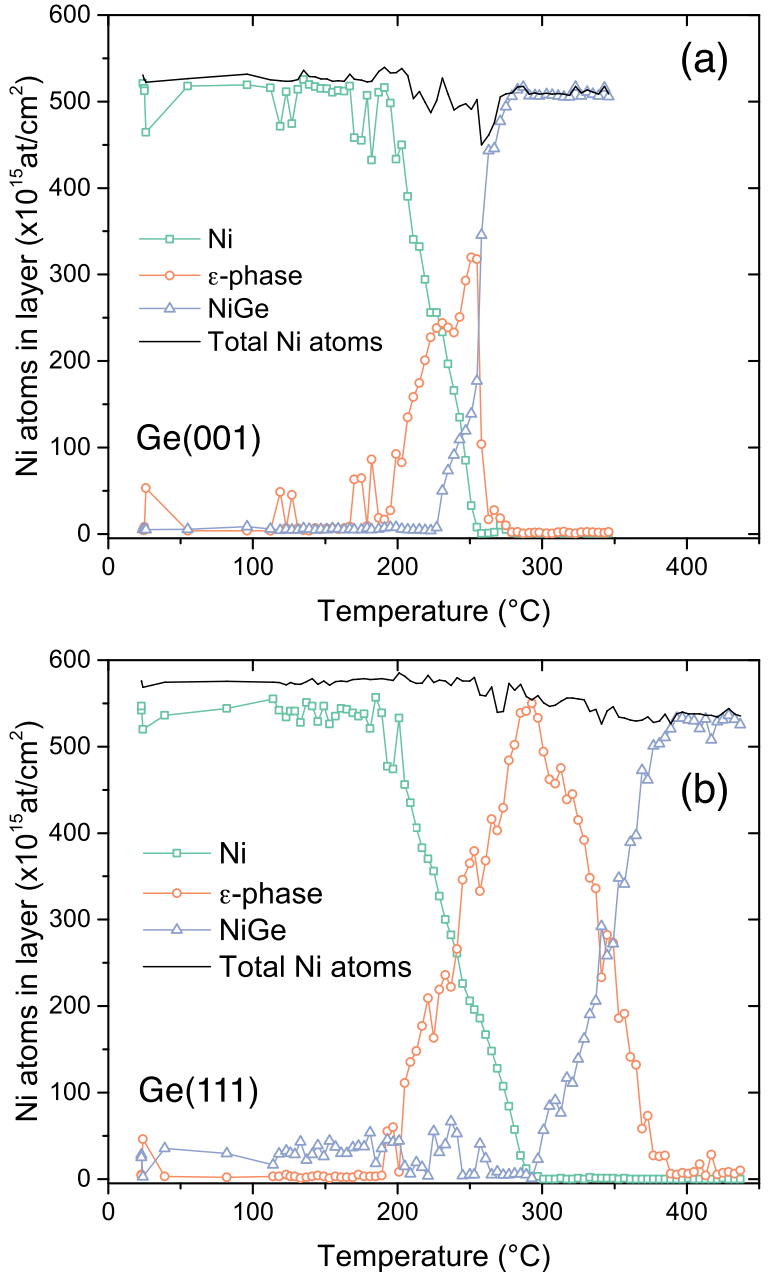

FIG. 9. Thickness evolution of the different phases during the ramp anneal of a $60 \mathrm{~nm} \mathrm{Ni}$ film at $2{ }^{\circ} \mathrm{C} / \mathrm{min}$ on (a) $\mathrm{Ge}(001)$ and (b) $\mathrm{Ge}(111)$. The thicknesses are fitted from the in situ RBS data using an artificial neural network (ANN) approach and are expressed in $\mathrm{Ni}$ atoms $/ \mathrm{cm}^{2}$ for normalization purposes.

can be the as-deposited formation of only a very thin crystalline $\epsilon$-phase layer in contact with the interface within the intermixed layer. The vertical growth of this crystalline layer could then be slow as it depends on diffusion through this intermixed layer. The extended temperature window over which the presence of the $\epsilon$-phase was detected in the XRD measurements is also visible in the RBS results. While the $\epsilon$-phase is completely consumed around $260{ }^{\circ} \mathrm{C}$ on $\mathrm{Ge}(001)$, it remains present up until almost $400^{\circ} \mathrm{C}$ on $\mathrm{Ge}(111)$.

According to the RBS results on the $\mathrm{Ge}(001)$ substrate (Figure 9(a)), the NiGe phase starts growing around $230^{\circ} \mathrm{C}$. At that time, the $\mathrm{Ni}$ is not yet fully consumed by the $\epsilon$-phase, which is still growing, indicating that both phases grow simultaneously until the $\mathrm{Ni}$ is completely consumed by the $\epsilon$-phase around $260^{\circ} \mathrm{C}$. This simultaneous growth of the $\epsilon$-phase and NiGe has also been observed by Gaudet et al. for a $30 \mathrm{~nm} \mathrm{Ni}$ film on $\mathrm{Ge}(001)$ and amorphous Ge during a $3{ }^{\circ} \mathrm{C} / \mathrm{s}$ ramp anneal ${ }^{10}$ and by Nemouchi et al. on amorphous and polycrystalline $\mathrm{Ge}$ substrates during an isothermal anneal at $160^{\circ} \mathrm{C}^{8,9}$ On the $\mathrm{Ge}(111)$ substrate, the RBS results show that $\mathrm{NiGe}$ only starts growing when the $\epsilon$-phase reaches its maximum thickness, i.e., when all $\mathrm{Ni}$ has been 
transformed into the $\epsilon$-phase (Figure 9(b)). This implies sequential growth of both phases on this substrate orientation, which was also put forward by Gaudet et al. ${ }^{10}$ However, on the pole figure quenched at $310^{\circ} \mathrm{C}$ on the $\mathrm{Ge}(111)$ substrate (see Figure 6) faint diffraction spots from the $\mathrm{NiGe}$ are already visible, while the fiber ring from the pure Ni layer can also still be weakly observed. This suggests that simultaneous growth of both phases also takes place on a $\mathrm{Ge}(111)$ substrate, although a simultaneous thickness increase of the NiGe phase is not observed in the RBS results on this substrate orientation. This is possibly due to the fact that the $\epsilon$-phase grows at the $\mathrm{NiGe} / \epsilon$-phase interface by consuming $\mathrm{NiGe}$ as long as pure $\mathrm{Ni}$ is still available. As such, the NiGe phase is growing at the $\mathrm{Ge} / \mathrm{NiGe}$ interface and is being consumed at the $\mathrm{NiGe} / \epsilon$-phase interface at the same time, resulting in its thickness staying more or less constant (and below the detection limit of the RBS setup). Once the Ni supply is exhausted, the NiGe continues to grow by consuming the $\epsilon$-phase and its thickness starts to increase. This same phase competition is possibly happening on the $\mathrm{Ge}(001)$ substrate too, but different growth rates for both phases on that substrate orientation might allow the NiGe to grow thicker on $\mathrm{Ge}(001)$, while pure $\mathrm{Ni}$ is still present (thus, above the RBS detection limit). These different growth rates might result from the different orientation of both phases on either $\mathrm{Ge}(001)$ or $\mathrm{Ge}(111)$, which results in different interface energies and different diffusion coefficients for $\mathrm{Ni}$ in both phases on $\mathrm{Ge}(001)$ vs. $\mathrm{Ge}(111)$.

Lastly, the large temperature interval for $\epsilon$-phase growth and the high relative thickness that is reached by this phase on the Ge(111) substrate allows us to look at the variation of the Ni:Ge ratio in this phase as a function of the annealing temperature. This is plotted in Figure 10 for the temperature window between 240 and $360^{\circ} \mathrm{C}$, i.e., centered around the temperature where the pure Ni layer is completely consumed (around $290^{\circ} \mathrm{C}$ ). In this figure, the variation in Ge concentration in the $\epsilon$-phase is overlaid with its corresponding thickness (right y-axis, expressed in at $/ \mathrm{cm}^{2}$ ). These data suggest that the Ge concentration is somewhere between $34 \%$ and

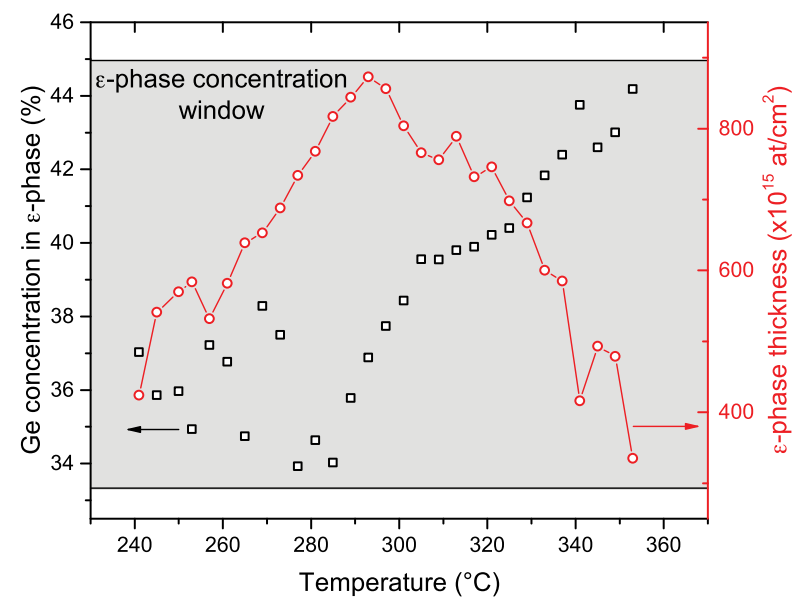

FIG. 10. Evolution of the Ge concentration within the $\epsilon$-phase as a function of temperature as fitted from the RBS data. The thickness of the $\epsilon$-phase is overlaid on the right $y$-axis. The grey area depicts the allowed concentration range for the $\epsilon$-phase according to the Ni-Ge binary phase diagram. ${ }^{21}$
$38 \%$ during the growth, which is around the concentration at the lowest temperatures where the $\epsilon$-phase can exist according to the bulk Ni-Ge phase diagram. ${ }^{21}$ This was confirmed in an additional ex situ RBS measurement with a higher resolution performed on an as-deposited sample, where it was observed that the Ge concentration in the initial intermixed Ni-Ge layer is around 37\% (data not shown). Once the maximum thickness is reached, the Ge concentration steadily rises as the $\epsilon$-phase is consumed by the growth of NiGe. This change in Ge concentration of the $\epsilon$-phase during its consumption by the growing NiGe phase explains at least partly the observed change in $2 \theta$ angle of the $\epsilon$-phase diffraction peak in the in situ XRD measurements once NiGe forms (see Figure 1). Indeed, according to Ellner et al., ${ }^{28}$ the lattice constants of the $\epsilon$-phase decrease when the Ni:Ge ratio becomes more Ge rich, which translates in a decrease of the $\epsilon(0002)$ and (10 $\overline{1} 1)$ lattice spacings and thus a shift towards higher $2 \theta$ angles for the corresponding diffraction peaks. Besides this effect, also stress and thermal expansion should be taken into account. Hence, a quantitative interpretation of this peak shift was not attempted based on the data collected in this work.

\section{Summary and conclusions}

We studied the phase formation sequence and texture evolution of nickel germanides forming during a ramp anneal of a thin $\mathrm{Ni}$ film on $\mathrm{Ge}(001)$ and $\mathrm{Ge}(111)$ oriented substrates. The phase formation sequence was determined using in situ XRD and in situ RBS and is summarized in Figure 11. The temperature windows over which the different phases are present are marked by the horizontal bars. The temperature scale in the figure is based on the $1{ }^{\circ} \mathrm{C} / \mathrm{s}$ ramp rate used for the in situ XRD results. The shaded areas of these bars indicate the temperature ranges over which the specific phase is growing (as deduced from the RBS measurements). It was found that the general phase sequence on both substrate orientations is as follows:

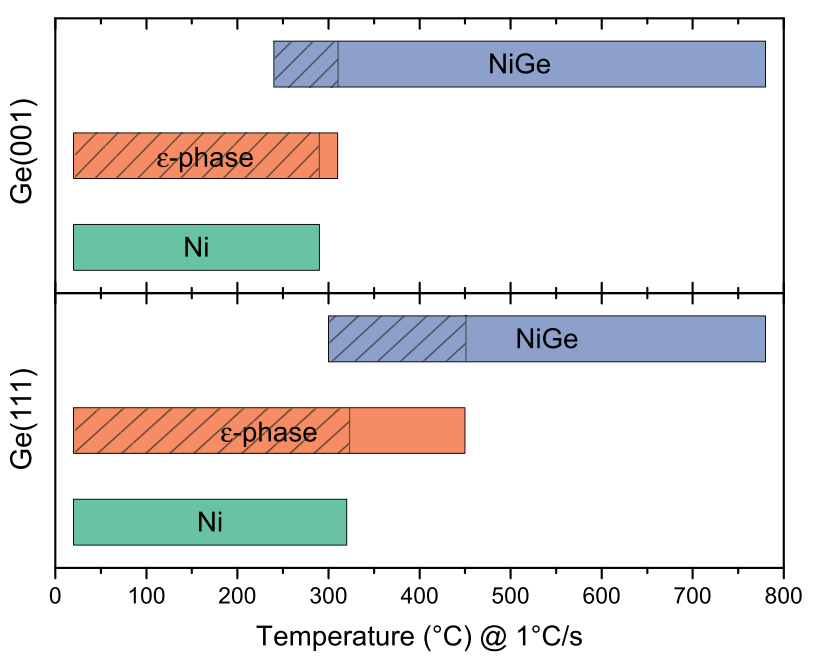

FIG. 11. Summary of the phase formation sequence for a $30 \mathrm{~nm}$ Ni film deposited on $\mathrm{Ge}(001)$ and $\mathrm{Ge}(111)$ during a ramp anneal at $1^{\circ} \mathrm{C} / \mathrm{s}$. The horizontal bars indicate the temperature ranges over which the different phases are present. The shaded areas represent the temperatures at which the specific phase is growing. 


$$
\mathrm{Ni} \rightarrow \epsilon-\text { phase } \rightarrow \mathrm{NiGe} .
$$

The unambiguous identification of the transient Ni-rich germanide as the hexagonal, metastable $\epsilon$-phase was done using XRD pole figure measurements. On both substrate orientations, the texture of this phase is characterized by two epitaxial components. Furthermore, weak $\epsilon$-phase diffraction features were observed in pole figures collected on asdeposited samples, suggesting that small nuclei of this phase already form within the intermixed $\mathrm{Ni}-\mathrm{Ge}$ region that forms at the interface during deposition of the Ni film.

In situ RBS was used to study the kinetics during the phase formation sequence. Our results indicate the simultaneous growth of the $\epsilon$-phase and $\mathrm{NiGe}$ on a $\mathrm{Ge}(001)$ substrate (also observed in previous studies), whereas on $\mathrm{Ge}(111)$, simultaneous growth of these phases could not be observed by RBS. However, pole figures collected on a sample quenched at the very onset of $\mathrm{NiGe}$ growth do reveal the simultaneous presence of very thin layers of $\mathrm{Ni}$ and $\mathrm{NiGe}$, suggesting that the growing $\mathrm{NiGe}$ is consumed by the $\epsilon$-phase as long as pure $\mathrm{Ni}$ is present.

Finally, the results obtained in this work indicate that the incorrect identification of the transient phase on single crystal Ge substrates from past studies can be attributed to the limited information that is gained from the standard $\theta / 2 \theta$ geometry used for in situ XRD measurements in case of textured phases, because only planes (almost) parallel to the substrate holder are measured. Hence, texture measurements combined with compositional depth profiles (providing stoichiometry information) can provide valuable added insight when studying phase formation on single crystal substrates.

\section{ACKNOWLEDGMENTS}

The authors thank the FWO-vlaanderen, BOF-UGent (under Contract No. "GOA 01G01513") and the Hercules Foundation (under Project No. "AUGE/09/014") for financial support. S. Bals acknowledges financial support from European Research Council (ERC Starting Grant No. “\#335078-COLOURATOMS"). A. Vantomme thanks the BOF-KULeuven (under Contract No. "GOA/14/007") and the Joint Science and Technology Collaboration between the FWO (G.0031.14) and NRF (UID88013). The National Synchrotron Light Source (NSLS), Brookhaven National Laboratory, was supported by the U.S. Department of Energy, Office of Basic Energy Sciences (Contract No. DEAC02-98CH10886).

${ }^{1}$ P. Goley and M. Hudait, Materials 7, 2301 (2014).

${ }^{2}$ Y. Kamata, Mater. Today 11, 30 (2008).

${ }^{3}$ D. P. Brunco, B. De Jaeger, G. Eneman, J. Mitard, G. Hellings, A. Satta, V. Terzieva, L. Souriau, F. E. Leys, G. Pourtois, M. Houssa, G. Winderickx, E. Vrancken, S. Sioncke, K. Opsomer, G. Nicholas, M. Caymax, A. Stesmans, J. Van Steenbergen, P. W. Mertens, M. Meuris, and M. M. Heyns, J. Electrochem. Soc. 155, H552 (2008).

${ }^{4}$ R. Pillarisetty, Nature 479, 324 (2011).

${ }^{5}$ Q. Xie, S. Deng, M. Schaekers, D. Lin, M. Caymax, A. Delabie, X.-P. Qu, Y.-L. Jiang, D. Deduytsche, and C. Detavernier, Semicond. Sci. Technol. 27, 074012 (2012).
${ }^{6}$ S. Gaudet, C. Detavernier, A. J. Kellock, P. Desjardins, and C. Lavoie, J. Vac. Sci. Technol. A 24, 474 (2006).

${ }^{7}$ J. K. Patterson, B. J. Park, K. Ritley, H. Z. Xiao, L. H. Allen, and A. Rockett, Thin Solid Films 253, 456 (1994).

${ }^{8}$ F. Nemouchi, D. Mangelinck, C. Bergman, G. Clugnet, P. Gas, and J. L. Lábár, Appl. Phys. Lett. 89, 131920 (2006).

${ }^{9}$ F. Nemouchi, D. Mangelinck, J. L. Lábár, M. Putero, C. Bergman, and P. Gas, Microelectron. Eng. 83, 2101 (2006).

${ }^{10}$ S. Gaudet, C. Detavernier, C. Lavoie, and P. Desjardins, J. Appl. Phys. 100, 034306 (2006).

${ }^{11}$ Y. F. Hsieh, E. D. Marshall, and S. S. Lau, Thin Solid Films 162, 287 (1988).

${ }^{12}$ L. J. Jin, K. L. Pey, W. K. Choi, E. A. Fitzgerald, D. A. Antoniadis, A. J. Pitera, M. L. Lee, D. Z. Chi, and C. H. Tung, Thin Solid Films 462-463, 151 (2004).

${ }^{13}$ F. Geenen, W. Knaepen, K. De Keyser, K. Opsomer, R. Vanmeirhaeghe, J. Jordan-Sweet, C. Lavoie, and C. Detavernier, Thin Solid Films 551, 86 (2014).

${ }^{14}$ F. Geenen, W. Knaepen, J. Demeulemeester, K. De Keyser, J. JordanSweet, C. Lavoie, A. Vantomme, and C. Detavernier, J. Alloys Compd. 611, 149 (2014).

${ }^{15}$ K. De Keyser, R. L. Van Meirhaeghe, C. Detavernier, J. Jordan-Sweet, and C. Lavoie, J. Electrochem. Soc. 157, H395 (2010).

${ }^{16}$ J. Demeulemeester, D. Smeets, C. Van Bockstael, C. Detavernier, C. M. Comrie, N. P. Barradas, A. Vieira, and A. Vantomme, Appl. Phys. Lett. 93, 261912 (2008)

${ }^{17}$ J. Demeulemeester, D. Smeets, C. M. Comrie, N. P. Barradas, A. Vieira, C. Van Bockstael, C. Detavernier, K. Temst, and A. Vantomme, J. Appl. Phys. 113, 163504 (2013).

${ }^{18}$ A. Schrauwen, J. Demeulemeester, A. Kumar, W. Vandervorst, C. M. Comrie, C. Detavernier, K. Temst, and A. Vantomme, J. Appl. Phys. 114, 063518 (2013).

${ }^{19}$ Joint Committee on Powder Diffraction Standards (JCPDS), Powder Diffraction File 00-024-0449.

${ }^{20}$ B. De Schutter, W. Devulder, A. Schrauwen, K. van Stiphout, T. Perkisas, S. Bals, A. Vantomme, and C. Detavernier, Microelectron. Eng. 120, 168 (2014).

${ }^{21}$ A. Nash and P. Nash, Bull. Alloy Phase Diagrams 8, 255 (1987).

${ }^{22}$ A.-K. Larsson and R. Withers, J. Alloys Compd. 264, 125 (1998).

${ }^{23}$ See supplementary material at http://dx.doi.org/10.1063/1.4945317 for Figures S1, S2, S3(a), S3(b), and S4.

${ }^{24}$ K. De Keyser, C. Van Bockstael, C. Detavernier, R. L. Van Meirhaeghe, J. Jordan-Sweet, and C. Lavoie, Electrochem. Solid-State Lett. 11, H266 (2008).

${ }^{25}$ C. Van Bockstael, C. Detavernier, R. L. Van Meirhaeghe, J. Jordan-Sweet, and C. Lavoie, J. Appl. Phys. 106, 064515 (2009).

${ }^{26}$ S. Gaudet, C. Coia, P. Desjardins, and C. Lavoie, J. Appl. Phys. 107, 093515 (2010).

${ }^{27}$ S. Gaudet, P. Desjardins, and C. Lavoie, J. Appl. Phys. 110, 113524 (2011).

${ }^{28}$ M. Ellner, T. Gödecke, and K. Schubert, J. Less-Common Met. 24, 23 (1971).

${ }^{29}$ C. Detavernier, A. S. Ozcan, J. Jordan-Sweet, E. A. Stach, J. Tersoff, F. M. Ross, and C. Lavoie, Nature 426, 641 (2003).

${ }^{30}$ F. M. d'Heurle, J. Mater. Res. 3, 167 (1987).

${ }^{31}$ F. M. d'Heurle and P. Gas, J. Mater. Res. 1, 205 (1986).

${ }^{32}$ R. T. Tung, J. M. Poate, J. C. Bean, J. M. Gibson, and D. C. Jacobson, Thin Solid Films 93, 77 (1982).

${ }^{33} \mathrm{~K}$. De Keyser, "Texture of thin silicide and germanide films," Ph.D. thesis, Ghent University, 2011.

${ }^{34}$ L. J. Chen, Mater. Sci. Eng., R 29, 115 (2000).

${ }^{35}$ J. Demeulemeester, D. Smeets, C. M. Comrie, C. Van Bockstael, W. Knaepen, C. Detavernier, K. Temst, and A. Vantomme, J. Appl. Phys. 108, 043505 (2010).

${ }^{36}$ C. M. Comrie, D. Smeets, K. J. Pondo, C. v. der Walt, J. Demeulemeester, W. Knaepen, C. Detavernier, A. Habanyama, and A. Vantomme, Thin Solid Films 526, 261 (2012).

${ }^{37}$ J. Demeulemeester, D. Smeets, N. P. Barradas, A. Vieira, C. M. Comrie, K. Temst, and A. Vantomme, Nucl. Instrum. Methods Phys. Res., B 268, $1676(2010)$

${ }^{38}$ N. P. Barradas, C. Jeynes, and R. P. Webb, Appl. Phys. Lett. 71, 291 (1997). 